\title{
Zingiber officinale Roscoe Prevents DNA Damage and Improves Muscle Performance and Bone Integrity in Old Sprague Dawley Rats
}

\author{
Suzana Makpol ${ }^{D},{ }^{1}$ Nur Fathiah Abdul Sani ${ }^{D},{ }^{1}$ Nur Haleeda Hakimi ${ }^{(D)}{ }^{1}$ \\ Nazirah Ab Rani (D), ${ }^{1}$ Siti Nor Asyikin Zakaria (D), $^{1}$ Ahmad Fais Abd Rasid $\left(\mathbb{D},{ }^{1}\right.$ \\ Geetha Gunasekaran $\left(\mathbb{D},{ }^{1}\right.$ Nur Fatin Nabilah Mohd Sahardi ${ }^{D},{ }^{1}$ Jen Kit Tan $\left(\mathbb{D},{ }^{1}\right.$ \\ Norzana Abd Ghafar $\left(\mathbb{D},{ }^{2}\right.$ and Mariam Firdhaus Mad Nordin ${ }^{3}{ }^{3}$ \\ ${ }^{1}$ Department of Biochemistry, Faculty of Medicine, Level 17 Preclinical Building, UKM Medical Center, Jalan Yaacob Latif, \\ Bandar Tun Razak, Cheras, Kuala Lumpur 56000, Malaysia \\ ${ }^{2}$ Department of Anatomy, Faculty of Medicine, Level 18 Preclinical Building, UKM Medical Center, Jalan Yaacob Latif, \\ Bandar Tun Razak, Cheras, Kuala Lumpur 56000, Malaysia \\ ${ }^{3}$ Department of Chemical Process Engineering, Universiti Teknologi Malaysia (UTM) Kuala Lumpur, Jalan Sultan Yahya Petra, \\ Kuala Lumpur 54100, Malaysia
}

Correspondence should be addressed to Suzana Makpol; suzanamakpol@ppukm.ukm.edu.my

Received 26 May 2020; Accepted 16 July 2020; Published 5 August 2020

Guest Editor: Arham Shabbir

Copyright (C) 2020 Suzana Makpol et al. This is an open access article distributed under the Creative Commons Attribution License, which permits unrestricted use, distribution, and reproduction in any medium, provided the original work is properly cited.

\begin{abstract}
Age-related loss of skeletal muscle mass and strength or sarcopenia is attributed to the high level of oxidative stress and inadequate nutritional intake. The imbalance in oxidative status with increased production of free radicals results in damage to the DNA which leads to cell dysfunction. This study aimed to determine the effect of Zingiber officinale Roscoe (ginger) on muscle performance and bone integrity in Sprague Dawley (SD) rats. SD rats aged three (young), nine (adult), and twenty-one (old) months old were treated with either distilled water or ginger extract at a concentration of $200 \mathrm{mg} / \mathrm{kg}$ body weight (BW) daily for 3 months via oral gavage. Muscle performance was assessed at 0,1,2, and 3 months of treatment by measuring muscle strength, muscle function, and bone integrity while DNA damage was determined by comet assay. Muscle cell histology was analyzed by hematoxylin and eosin (H\&E) staining. Young and adult ginger-treated rats showed a significant improvement in muscle strength after 3 months of supplementation. Bone mineral density (BMD) and bone mineral content (BMC) were increased while fat free mass (FMM) was decreased after 3 months of ginger supplementation in young rats but not changed in adult and old ginger supplemented groups. Interestingly, supplementation of ginger for 3 months to the old rats decreased the level of damaged DNA. Histological findings showed reduction in the size of muscle fibre and fascicles with heterogenous morphology of the muscle fibres indicating sarcopenia was evident in old rats. Treatment with ginger extract improved the histological changes even though there was evidence of cellular infiltration (mild inflammation) and dilated blood vessels. In conclusion, Z. officinale Roscoe prevents DNA damage and improves muscle performance and bone integrity in SD rats indicating its potential in alleviating oxidative stress in ageing and thus delaying sarcopenia progression.
\end{abstract}

\section{Introduction}

Sarcopenia is a common disease that occurs among the elderly which normally affect people aged 60 years old and above. This disease is related to the loss of skeletal muscle mass and strength which occurs with advancing age [1]. Statistics has shown that 5 to $13 \%$ of elderly, aged 60 to 70 years, are affected by sarcopenia [2]. This number increases to 11 to $50 \%$ for those aged 80 years and above. A previous study showed that this muscle deterioration commonly 
occurred among older males as compared to females [3] which could be characterized by the decrement of muscle mass, muscle strength, and physical performance [4]. Currently, sarcopenia has become a greater problem among the elderly because this disease contributes to the reduction of life expectancies by increasing the risk of frailty, fall, morbidity, and mortality. The cause of sarcopenia is multifactorial which involves genetic, physiological, and environmental factors. It can be attributed to the high level of oxidative stress, hormonal changes, sedentary lifestyle, and inadequate nutritional intake [5]. However, high level of oxidative stress is the main contributor to this muscle deterioration disease [6].

Oxidative stress refers to the imbalance between reactive oxygen species (ROS) production and antioxidant defence [7]. ROS including hydrogen peroxide $\left(\mathrm{H}_{2} \mathrm{O}_{2}\right)$, hydroxyl radical (.OH), nitric oxide $(\mathrm{NO})$, and superoxide anion $\left(\mathrm{O}^{2-}\right)$ can be produced from endogenous sources such as mitochondria, endoplasmic reticulum, and cytochrome $\mathrm{c}$ as well as from exogenous sources such as pollution, ultra violet (UV) light, and heavy metals $[8,9]$. Excessive production of ROS in the body will result in oxidative damage to several types of biological molecules such as proteins, DNA, carbohydrates, and lipids. Oxidative damage to DNA and protein could cause alteration of DNA transcription as well as loss of DNA repair capacity [10]. Meanwhile, oxidative damage to lipids results in increment of lipid peroxidation [11]. The accumulation of these molecular damages could lead to mitochondrial dysfunction, mutation, alteration of cell growth, and differentiation as well as apoptosis. Finally, the accumulation of these damages could alter the balance between synthesis and degradation of skeletal muscle protein which contributes to the pathogenesis of loss of muscle mass disease including sarcopenia [12]. Currently, several strategies have been introduced in order to combat these conditions such as nutritional supplements, hormonal therapy, and physical exercise which have shown positive effects on muscle mass and strength [13-15].

Ginger (Zingiber officinale Roscoe) is one of the traditional herbs or spices that has been studied as an antioxidant agent against oxidative stress in the pathogenesis of degenerative diseases. Ginger consists of several bioactive compounds such as 6-gingerol, 6-shogaol, 10-gingerol, gingerdiones, gingerdiols, paradols, 5 diacetoxy-6-gingerdioal, and 12-gingerol that contribute to many therapeutic effects including antioxidant, antibacterial, anticancer, antiinflammatory, antidiabetic, neuroprotective, and gastroprotective [16-18].

A previous study showed that ginger extract could exhibit inhibitory effect against $\alpha$-amylase, $\alpha$-glucosidase, and angiotensin-converting enzyme (ACE) activity in type 2 diabetes mellitus rats [19]. Ginger extract also prevented lipid peroxidation, inhibited ACE activity, and reversed the expression of inflammatory cytokines and lipid in cardiovascular rats [20, 21]. A study carried out by Park et al. [22] found that 6-shogoal in ginger extract had the ability to improve the formation of synapse in the brain and inhibit components of inflammatory pathway such as tumour necrosis alpha (TNF- $\alpha$ ), nitric oxide (NO), cyclooxygenase- 2
(COX-2), and inducible nitric oxide synthase (iNOS) in the in vivo Parkinson disease model. This finding was similar to the result from another study performed by $\mathrm{Ha}$ et al. [23].

However, no study has been reported which investigated the effect of ginger extract in improving muscle performance in ageing. Thus, this study aimed to elucidate the effect of $Z$. officinale Roscoe in improving muscle performance in Sprague Dawley (SD) rats.

\section{Materials and Methods}

2.1. Zingiber officinale Roscoe Preparation. Fresh ginger was harvested from Bentong, Pahang, Malaysia. The extraction process was carried out at Department of Chemical Process Engineering, Universiti Teknologi Malaysia (UTM, Kuala Lumpur, Malaysia), and ERP Two One Technologies \& Innovations Sdn Bhd (Subang, Malaysia). Standardized ginger extract was isolated by using the subcritical water extraction method at optimum temperature of $130^{\circ} \mathrm{C}$ for $30 \mathrm{~min}$ with the solvent to solid ratio at $28 / 2 \mathrm{ml} / \mathrm{mg}$ [24]. The extract contains 6-gingerol and 6-shogaol at concentrations of $289.531 \mathrm{mg} / \mathrm{mL}$ and $15.466 \mathrm{mg} / \mathrm{mL}$, respectively. Ginger was freeze-dried to form powder and stored at $-20^{\circ} \mathrm{C}$ before use.

2.2. Animals. For the main study, the SD rats were divided into three groups: 18 male young 3-month-old SD rats, 18 male adult 9-month-old SD rats, and 18 male aged 21month-old SD rats. The rats were purchased from Universiti Kebangsaan Malaysia Laboratory Animal Resource Unit (LARU). Each age group of rats was further allotted into two groups: Group 1 was control group which was given $1 \mathrm{ml}$ of distilled water $(n=8)$ and Group 2 was given $200 \mathrm{mg} / \mathrm{kg} /$ body weight (BW) daily of $Z$. officinale Roscoe $(n=10)$ for three months. Each rat was randomly kept in individual Sealsafe ${ }^{\circledR}$ Plus Rat IVC Green Line (TECHNIPLAST, Varese, Italy) cage in animal care facility and allowed to acclimatize for one week before administration of the treatment. Throughout the study, the rats were maintained in animal care facilities with temperature of $24^{\circ} \mathrm{C}$ and $12 \mathrm{~h}$ of light and dark cycle. The rats were also provided with rat pellet (Gold Coin, Malaysia) and water ad libitum. The rat pellet is composed of minimum $22.0 \%$ crude protein content, maximum $5.0 \%$ crude fibre content, minimum $3.0 \%$ crude fat content, maximum $13.0 \%$ moisture, maximum $8.0 \%$ ash, $0.8 \%-1.2 \%$ calcium, $0.6 \%-1.0 \%$ phosphorus, and approximately $49.0 \%$ nitrogen-free extract. Kenaff (Muhaaz Enterprise, Terengganu Malaysia) was used as the bedding of the rats which was changed twice per week. The animals were tested based on their groups, starting from Group 1 and followed by Group 2 for each test performed. The experimental design was consented by the Universiti Kebangsaan Malaysia Animal Ethics Committee (UKMAEC Approval Number: BIOK/PP/2018/SUZANA/14-MAY/924-JUNE2018-MAY-2020). The experimental protocol for this research is depicted in Figure 1. The number of animals was chosen based on previous study that used seven rats for control and eight rats for the treated group to study the effect 


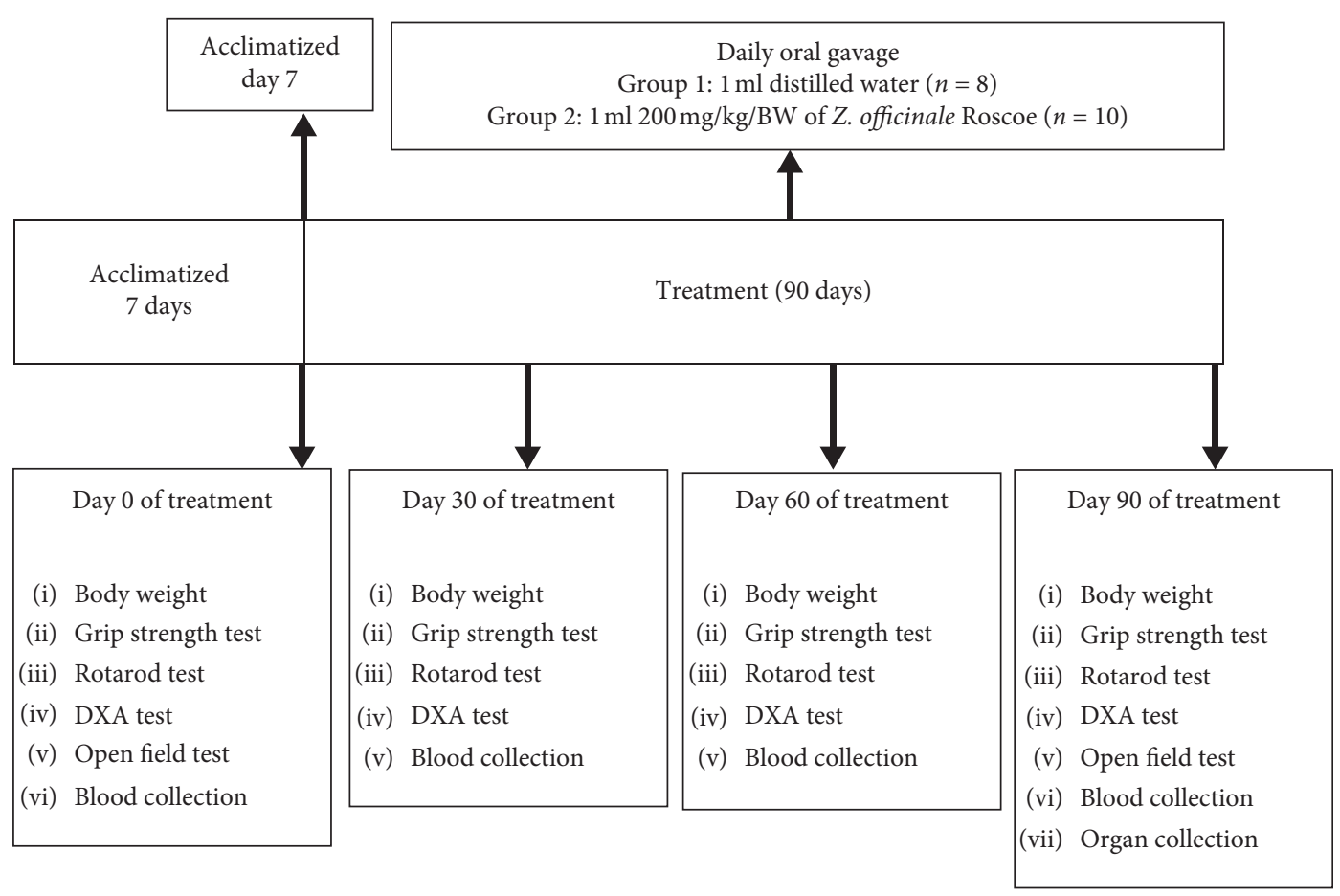

Figure 1: The timeline for the experimental protocol.

of gelam honey and ginger, along with the approval from UKMAEC [25].

2.3. Pilot Study. In the pilot study, three female rats were used. The main purpose of this pilot study was to select the optimum dosage to be used in the main study and to minimize the number of rats to be used. The starting dosage of Z. officinale Roscoe in this pilot study was $5 \mathrm{mg} / \mathrm{kg} / \mathrm{BW}$ followed by 50,300 , and $2000 \mathrm{mg} / \mathrm{kg} / \mathrm{BW}$ sequentially for every five days. Blood was drawn on days $6,11,16$, and 21 for liver function test.

2.4. Clinical Observations. The rats were observed individually at $0.5,1,2,3$, and $4 \mathrm{~h}$ after administration of $Z$. officinale Roscoe extract. The rats were then observed after $24 \mathrm{~h}$, followed by observation twice daily thereafter for the duration of 21 days for mortality and clinical toxicity signs. The signs of clinical toxicity include changes on skin, fur, eyes, and mucous membrane, behavioural pattern, tremors, salivation, diarrhoea, occurrence of secretion, excessive grooming, repetitive circling, and bizarre behaviour such as self-mutilation and walking backwards. Throughout the experimentation, the rats were also closely monitored for any signs of pain which include excessive licking or scratching, redness and swelling at any site, anorexia which was indicated by the absence of faeces, struggling, squealing, convulsions, twitching, tremors, weakness, teeth grinding, hunched up, unwilling to move, and favouring a limb. The other signs of pain include decrease in appetite which were evidence by few faeces, biting of affected body part, reluctant to move, increased respiration, change in bowel or urinary activities, and porphyrin discharge which was shown by red-brown pigment around eyes and nostrils. The BW for each rat was recorded on days 0 (prior to dosing), 6, 11, 16, and 21 .

2.5. Acute Toxicity Study. Twelve female SD rats were used in the toxicity study. From the pilot study, it was found that the highest dose of $2000 \mathrm{mg} / \mathrm{kg} / \mathrm{BW} Z$. officinale Roscoe extract did not cause mortality and toxicity signs. Thus, the dosage of $200 \mathrm{mg} / \mathrm{kg} / \mathrm{BW}$ Z. officinale Roscoe extract was selected for the main study. Thus, this dose was used for acute toxicity study and treatment was given either orally once (single unrepeated dose) or orally daily (repeated dose) for 14 days. The extract was freshly prepared before administration and calculated based on the current BW of the rat. The rats were then observed individually at $0.5,1,2,3,4$, and $24 \mathrm{~h}$, followed by observation twice daily thereafter for the duration of 14 days for mortality and clinical toxicity signs. The BW for each rat was recorded on days 0 (prior to dosing), 7 , and 14 . Blood was also collected on days 0,7 , and 14 for liver function test. After the animals were sacrificed, all organs were then collected, weighted, and observed for any sign of toxicity.

2.6. Grip Strength Test. The front paws and hind paws grip strength were measured using Bioseb's Grip Strength Test (USA) machine. The grip strength was used to determine the maximal peak force developed by a rat when it pulled out the metal bar. The machine was set up on a strong and stable table. The rat was allowed to grasp the metal bar by its front paws when it was pulled by the tail backwards in horizontal plane. Peak tension, the force applied to the bar just before it loses grip, was recorded in grams unit. The rats were pulled 
three times and the machine would record the highest peak tension. Then, the same procedure was repeated for the hind paw grip strength measurement.

2.7. Rotarod Test. An automated rotarod (Med Associates, St. Albans, VT, USA) was used to assess muscle function by evaluating grip strength and balance. Each rat was placed on the rotating cylinder with a constant speed rotation (16 rpm) over $300 \mathrm{~s}$ where they had to walk to maintain their position on the cylinder. Test ended when rat fell from the rod, and the latency to fall was recorded ( $\max 300 \mathrm{~s}$ ). Each rat was tested three times with $10 \mathrm{~min}$ of rest between each test. Data are presented as the average of the three tests. The test was performed at $0,1,2$, and 3 months of supplementation.

\subsection{Measurement of Bone Mineral Density, Bone Mineral} Content, and Lean Bone Mineral Content. For the analysis of computerized tomography of bone density, the entire body of the rat was scanned by applying dual energy X-ray absorptiometry (DXA) (Hologic Discovery W, Bedford, USA). The rat was first anesthetized and left for 10 to $15 \mathrm{~min}$ for its sedative effect. The sedated rat was then laid down on the X-ray platform and scanning was performed within 3 min duration. As scanning was performed, a large radiating scanning arm was moved over the rats and a low-dose $\mathrm{X}$-ray beam was passed through the rats. These radiation changes were converted to the quantification of bone mineral density (BMD), bone mineral content (BMC), lean $\mathrm{BMC}$, and percentage of fat free mass (FFM) of each rat by the Hologic software.

2.9. Open Field Test. The rat was carried to the test room in its home cage and was handled by the base of their tails at all times. The open field test was carried out in a square and black painted wooden box of $60 \mathrm{~cm} \times 60 \mathrm{~cm}$. The rat was placed into one of the four corners facing towards the wall of the box and allowed to explore the field for 5 minutes in which its movement was recorded by a video camera mounted to the ceiling. The rat was simultaneously assessed using HVS Image Software 2017, based on the parameters of interest which include total path length and percentage of time moving. After the 5-minute test, the rat was returned to its home cage and the wooden box was wiped with $70 \%$ ethanol and permitted to dry between tests.

2.10. Blood Collection. Blood was withdrawn from each rat on days $0,30,60$, and 90 of treatment by orbital sinus collection methodology. The rat was anesthetized prior to blood collection and was handled with thumb and forefinger of the left hand. Skin around the rat's eye was pulled out until the eye bulged out and a capillary tube was inserted with slight thumb pressure into the medial canthus of the eye at $30^{\circ}$ angle to the nose. Blood was flown through the capillary tube after puncturing through the tissue and plexus/sinus. A total of $3 \mathrm{ml}$ of blood was collected into EDTA tube before gently removing the capillary tube. Bleeding was then stopped by applying a gentle pressure by the finger and wiped with sterile cotton. The collected blood was later centrifuged and plasma was kept in $-80^{\circ} \mathrm{C}$ freezer for further analysis.

2.11. Analysis of Damaged DNA by Comet Assay. Comet assay was performed as described by Singh et al. [26] with slight modification. Fully frosted microscope slides were coated with a thin layer of $0.6 \%$ normal melting point agarose (Sigma-Aldrich, St. Louise, MO, USA) and placed at room temperature for 10 minutes. Once the first agarose layer was solidified, a mixture of $5 \mu \mathrm{L}$ of whole blood with $0.6 \%$ low melting point agarose (Sigma-Aldrich, St. Louise, USA) was applied as the second layer. Then, the slides were immersed in chilled fresh lysing solution $(2.5 \mathrm{M} \mathrm{NaCI}$, $100 \mathrm{mM} \mathrm{Na}{ }_{2}$ EDTA-2H2O, $10 \mathrm{mM}$ Tris at pH 10, 1\% sodium N-lauroylsarcocinate, $1 \%$ Triton $\mathrm{X}-100$, and $10 \%$ dimethylsulfoxide) for $1 \mathrm{~h}$ at $4^{\circ} \mathrm{C}$. After lysis, the slides were placed in a horizontal electrophoresis tank filled with chilled fresh buffer $\left(0.3 \mathrm{M} \mathrm{NaOH}\right.$ and $1 \mathrm{mM} \mathrm{Na}_{2}$ EDTA) for 20 minutes to allow unwinding of the DNA followed by 20 minutes electrophoresis at $25 \mathrm{~V}$ with the current adjusted to $300 \mathrm{~mA}$. After electrophoresis, the slides were rinsed twice with neutralization buffer $(0.4 \mathrm{M}$ Tris Base, $\mathrm{pH} 7.5)$ to neutralize the excess alkali and were stained with ethidium bromide $(20 \mu \mathrm{g} / \mathrm{mL})$ (Sigma-Aldrich, St. Louise, MO, USA). Then, the slides were kept at room temperature to dry for later analysis. The slide was examined at 40x magnifications using a fluorescence microscope (Olympus, UK) where photomicrographs of 500 randomly selected nonoverlapping cells on each slide were captured. The slides of each rats were made in triplicate. All of the above procedures were performed in the dark. Comet images were analyzed using CASP software (CASP, Wroclaw, Poland). Percentages of tail DNA, tail length, tail moment, and olive tail moment were recorded to evaluate DNA damage.

2.12. Euthanization of Animals. The anaesthesia agents used in this study were KTX agents which are the combination of ketamine, xylazine, and zoletil-50 (tiletamine and zolazepam). The KTX agents were administered based on $0.1 \mathrm{ml} /$ $250 \mathrm{~g}$ of rat BW for each rat by intraperitoneal injection, at the lower right quadrant of the abdomen due to its rapidity, efficacy, and minimal pain, fear, and distress. The rats were then left for about 30 min for the KTX agents to give their sedative effect. This was observed by clinical signs, including disorientation and loss of consciousness, depression of respiration or rapid irregular breathing, progressively declined heart rate and blood pressure, urination, and defecation. Later, the rats were euthanized by decapitation method using decapitator (Modiezham Sdn. Bhd., Kuala Lumpur, Malaysia).

2.13. Collection of Organs. All rats were fastened overnight on day 90 before sacrificing for necropsy examination. The organs such as the heart, liver, kidneys, brain, and quadriceps muscle were dissected from the sacrificed rats. All organs were washed with $90 \%$ normal saline to remove any 
adherent tissue and later weighted. The weight of the organs was taken as quickly as possible to avoid drying, and they were analyzed in relative to the BW of the animals.

2.14. Histological Analysis. Quadriceps muscle tissues were fixated in $10 \%$ neutral formalin to preserve it permanently. The tissue was cut into small section and placed inside plastic cassette to hold the tissue while being processed by automated vacuum tissue processor (STP 120 Spin Tissue Processor, Thermo Fisher Scientific, Massachusetts, USA). Then, the tissue was embedded to be made as block of paraffin (Surgipath ${ }^{\circledR}$ Paraplast ${ }^{\circledR}$ from Leica Biosystems Richmond Inc., Illinois, USA). The tissue was later cut into section of $5 \mu \mathrm{M}$ by using Leica RM2135 Manual Rotary Microtome (Leica, Nussloch, Germany). The cut sections were then floated on a $38^{\circ} \mathrm{C}$ preheated warm water bath (Leica HI1210 Water Bath, Leica, Nussloch, Germany), before picking it up on glass microscopic slide. The glass slide with tissue section attached was further warmed at $50^{\circ} \mathrm{C}$ for 30 min in Memmert UN50 Universal Oven (Memmert, Buechenbach, Germany). Haematoxylin and eosin (H\&E) staining was then performed. The stained section of the slide was mounted by DPX mountant (VWR International Ltd., Poole, England) and covered with thin cover slides. The staining later was viewed under dissecting BX53 Microscope (Olympus, Tokyo, Japan) with built-in light source and camera attachment linked to LCD for the visualization of H\&E staining.

2.15. Statistical Analysis. All data were expressed as mean \pm standard deviation (SD); a $p$ value of $<0.05$ was considered statistically significant. SPSS software version 25 was used to carry out the statistical analysis. Data acquired were analyzed by using one-way ANOVA followed by a post hoc Bonferroni test.

\section{Results}

3.1. Clinical Observations. No physical and behavioural changes were observed on all treated rats after oral administration of $Z$. officinale Roscoe for 14 and 21 consecutive days in both pilot and toxicity studies. No mortality was recorded in both studies.

3.2. Rats' Body Weight of Pilot and Toxicity Studies. No change was observed on the BW of rats in the pilot study from day 0 till day 21 (Figure 2(a)). For acute toxicity study, the $\mathrm{BW}$ of the rats was retained throughout the study from day 0 till day 14 of the study (Figures 2(b) and 2(c)).

\subsection{Relative Organ Weight (ROW) of Pilot and Toxicity} Studies. The ROW of pilot study, single unrepeated dose of acute toxicity study, and daily dose of acute toxicity study is shown in Figure 3. The ROW of the lung for daily dose of acute toxicity study was significantly decreased compared to ROW of lung for pilot study $(p<0.05)$. However, the ROW of the liver for daily dose of acute toxicity study was significantly increased as compared to ROW of liver for pilot study $(p<0.05)$. The ROW of the brain for single unrepeated dose and daily dose of acute toxicity study was significantly decreased as compared to the ROW of the brain for pilot study $(p<0.05)$.

3.4. Liver Function Test. The liver function test for pilot and acute toxicity studies on various days is shown in Table 1 . The levels of total protein, albumin, globulin, albumin/ globulin ratio, total bilirubin, aspartate transaminase, alanine transaminase, alkaline phosphatase, and gamma-glutamyl transferase of rats in the pilot study and single unrepeated dose of toxicity study were not significantly different between the different days. However, the levels of total protein and globulin on days 7 and 14 of daily dose of toxicity study were significantly increased compared to day 0 and day 7 , respectively $(p<0.05)$.

3.5. Body Weight and Relative Organ Weight of Main Study. The BW of young, adult, and old rats was significantly increased within and between the group of treatments (Figure 4(a)). BW data were analyzed using a one-way repeated measure ANOVA followed by Bonferroni corrected $t$-test with $p$ value $<0.05$.

Measurement of the organ weight showed that the ROW of spleen and brain was significantly increased in young rats treated with ginger as compared to untreated control $(p<0.05)$ (Figure 4(b)). For old rats however, the ROW of right kidney was significantly decreased compared to untreated control $(p<0.05)$ (Figure $4(\mathrm{~d}))$.

3.6. Measurement of Grip Strength. The grip strength of front paws was significantly decreased at 3 months in control adult rats as compared to control young rats $(p<0.05)$ (Figure 5(a)). Treatment with ginger significantly increased the grip strength at 1,2 , and 3 months of young rats as compared to untreated control $(p<0.05)$. Treatment with ginger significantly increased the grip strength at 3 months of adults rats as compared to untreated control adult rats $(p<0.05)$.

The grip strength of hind paws was significantly increased at 0 and 2 months in young rats treated with ginger as compared to untreated control young rats $(p<0.05)$ (Figure 5(b)). A similar increase was observed in the grip strength at 0 months in control adult rats while it decreased at 3 months as compared to control young rats $(p<0.05)$. Treatment with ginger significantly increased the hind paws grip strength at 0 and 3 months in adult rats as compared to untreated control adult rats $(p<0.05)$. The grip strength of hind paws was significantly decreased at 1 and 3 months in control old rats as compared to control young rats $(p<0.05)$.

3.7. Measurement of Muscle and Bone Integrity. Muscle and bone integrity were represented by bone mineral content, bone mineral density, lean bone mineral content, and percentage of fat free mass (Figure 6). Bone mineral content was significantly decreased at 3 months in young rats treated with ginger as compared to untreated control young 

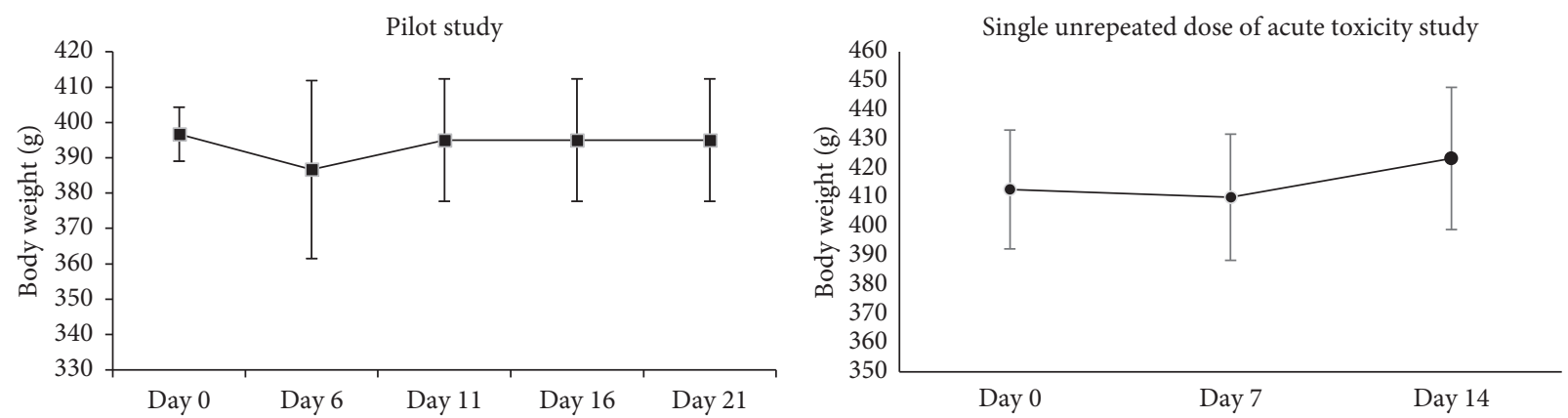

(a)

(b)

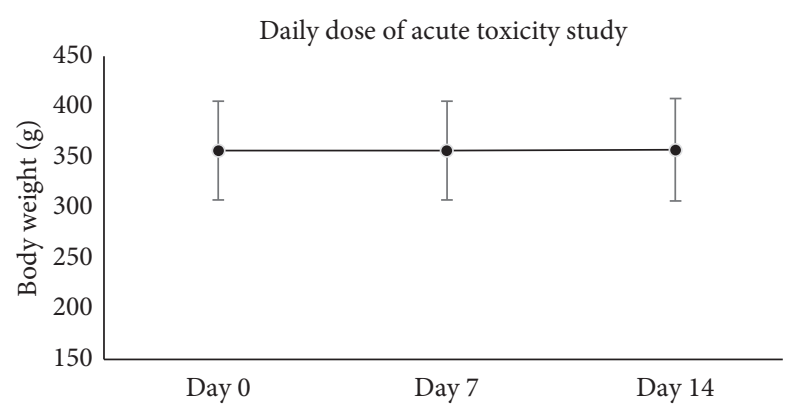

(c)

Figure 2: The body weight of (a) pilot study $(n=3)$, (b) single unrepeated dose of acute toxicity study $(n=6)$, and (c) daily dose of acute toxicity study $(n=6)$. The data are presented as mean \pm SD. No significant changes were found.

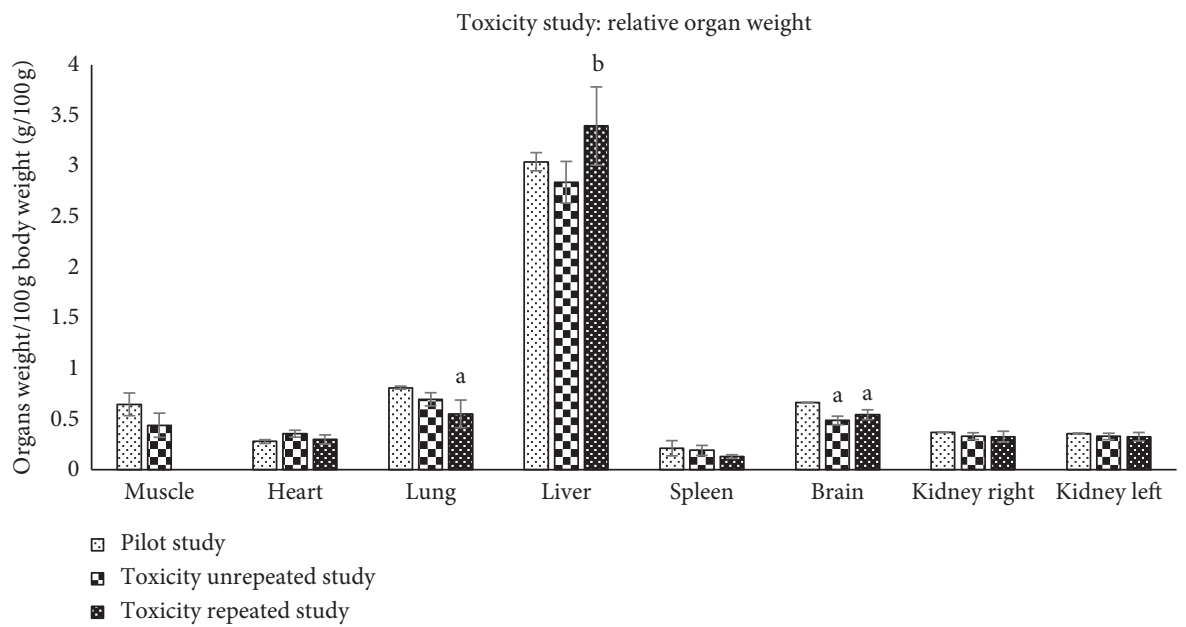

Figure 3: Relative organ weight of pilot study $(n=3)$, single unrepeated dose of acute toxicity study $(n=6)$, and daily dose of acute toxicity study $(n=6)$. The data are presented as mean \pm SD; ${ }^{a} p<0.05$, significantly different compared to pilot study; ${ }^{\mathrm{b}} p<0.05$, significantly different compared to single unrepeated dose of acute toxicity study, with a post hoc Bonferroni test.

rats $(p<0.05)$ (Figure 6(a)). In control adult rats, bone mineral content was significantly increased at 2 and 3 months while in control old rats it was significantly increased at 1,2, and 3 months as compared to control young rats $(p<0.05)$.

Bone mineral density was significantly decreased at 1 and 3 months in young rats treated with ginger as compared to untreated control young rats $(p<0.05)$ (Figure 6(b)). In control adult rats, bone mineral density was significantly increased at $0,1,2$, and 3 months while in control old rats, it was significantly increased at 0 and 1 month as compared to untreated control young rats $(p<0.05)$.

Lean bone mineral content was significantly decreased at 0,1 , and 3 months in young rats treated with ginger as compared to untreated control young rats $(p<0.05)$ (Figure 6(c)). In control adult rats, lean bone mineral content was significantly increased at 0,1 , and 3 months while in control old rats, it was significantly increased at 0,1 , and 3 months compared to untreated young control rats $(p<0.05)$. 
TABLE 1: The liver function test results of pilot study, single unrepeated dose of acute toxicity study, and daily dose of acute toxicity study.

\begin{tabular}{|c|c|c|c|c|c|c|c|c|c|}
\hline & Total protein & Albumin & Globulin & $\mathrm{A} / \mathrm{G}$ ratio & $\begin{array}{c}\text { Total } \\
\text { bilirubin }\end{array}$ & AST & ALT & $\begin{array}{c}\text { Alkaline } \\
\text { phosphatase }\end{array}$ & $\begin{array}{c}\text { Gamma } \\
\text { GT }\end{array}$ \\
\hline \multicolumn{10}{|c|}{ Pilot study, $n=3$} \\
\hline $\begin{array}{l}\text { Day } \\
0\end{array}$ & $84.00 \pm 1.00$ & $28.00 \pm 1.00$ & $56.00 \pm 1.00$ & $0.50 \pm 0.00$ & $2.28 \pm 0.99$ & $248.00 \pm 63.66$ & $84.00 \pm 17.44$ & $251.67 \pm 137.01$ & $4.00 \pm 0.00$ \\
\hline $\begin{array}{l}\text { Day } \\
6\end{array}$ & $74.00 \pm 6.56$ & $24.00 \pm 2.65$ & $50.00 \pm 6.93$ & $0.50 \pm 0.10$ & $1.71 \pm 0.00$ & $235.33 \pm 125.13$ & $94.00 \pm 27.87$ & $230.33 \pm 117.17$ & $4.00 \pm 0.00$ \\
\hline $\begin{array}{l}\text { Day } \\
11\end{array}$ & $89.67 \pm 8.62$ & $28.00 \pm 2.65$ & $61.67 \pm 6.03$ & $0.47 \pm 0.06$ & $1.71 \pm 0.00$ & $244.67 \pm 40.55$ & $100.33 \pm 26.56$ & $230.33 \pm 153.94$ & $4.00 \pm 0.00$ \\
\hline $\begin{array}{l}\text { Day } \\
16\end{array}$ & $88.67 \pm 22.05$ & $27.67 \pm 3.79$ & $61.00 \pm 18.33$ & $0.50 \pm 0.10$ & $2.85 \pm 1.97$ & $241.00 \pm 59.40$ & $111.33 \pm 20.40$ & $289.00 \pm 145.66$ & $4.00 \pm 0.00$ \\
\hline $\begin{array}{l}\text { Day } \\
21\end{array}$ & $65.00 \pm 0.00$ & $25.00 \pm 0.00$ & $40.00 \pm 0.00$ & $0.60 \pm 0.00$ & $1.71 \pm 0.00$ & $118.00 \pm 0.00$ & $80.00 \pm 0.00$ & $162.00 \pm 0.00$ & $4.00 \pm 0.00$ \\
\hline
\end{tabular}

Single unrepeated dose of acute toxicity study, $n=6$

$\begin{array}{llllllllll}\begin{array}{l}\text { Day } \\ 0\end{array} & 76.50 \pm 3.94 & 26.83 \pm 1.17 & 49.67 \pm 4.18 & 0.55 \pm 0.05 & 1.71 \pm 0.00 & 305.17 \pm 70.44 & 96.00 \pm 15.56 & 285.00 \pm 55.95 & 4.00 \pm 0.00 \\ \begin{array}{l}\text { Day } \\ 8\end{array} & 78.83 \pm 5.19 & 27.67 \pm 1.86 & 51.17 \pm 3.87 & 0.53 \pm 0.05 & 1.71 \pm 0.00 & 230.17 \pm 22.13 & 98.00 \pm 6.63 & 282.00 \pm 71.56 & 4.00 \pm 0.00 \\ \begin{array}{l}\text { Day } \\ 15\end{array} & 77.17 \pm 2.32 & 25.83 \pm 1.47 & 51.33 \pm 2.16 & 0.48 \pm 0.04 & 1.71 \pm 0.00 & 319.67 \pm 59.71^{\#} & 110.83 \pm 13.93 & 299.50 \pm 68.95 & 4.00 \pm 0.00\end{array}$

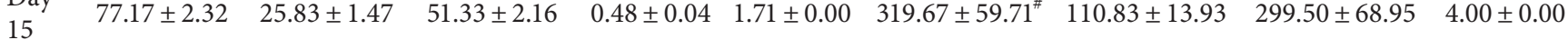

Daily dose of acute toxicity study, $n=6$

$\begin{array}{llllllllll}\text { Day } & 71.33 \pm 3.50 & 27.17 \pm 1.17 & 44.17 \pm 4.26 & 0.62 \pm 0.08 & 1.71 \pm 0.00 & 210.00 \pm 47.72 & 79.00 \pm 11.26 & 219.33 \pm 43.02 & 4.00 \pm 0.00 \\ 0 & & & & & & & & & \\ \text { Day } & 91.17 \pm 14.50^{*} & 30.67 \pm 2.94 & 60.50 \pm 11.91^{*} & 0.52 \pm 0.08 & 2.00 \pm 0.07 & 241.67 \pm 65.09 & 90.83 \pm 25.88 & 215.33 \pm 56.22 & 4.00 \pm 0.00 \\ 8 & & & & & & & & & \\ \text { Day } & 73.67 \pm 3.20^{\#} & 28.00 \pm 1.67 & 45.67 \pm 3.83^{\#} & 0.62 \pm 0.08 & 1.71 \pm 0.00 & 209.00 \pm 43.72 & 88.00 \pm 15.36 & 222.50 \pm 43.26 & 4.00 \pm 0.00 \\ 15 & & & & & & \end{array}$

The data are presented as mean $\pm \mathrm{SD} ;{ }^{*} p<0.05$, significantly different compared to day $0 ;{ }^{\#} p<0.05$, significantly different compared to day 8 , with a post hoc Bonferroni test.

Percentage of fat free mass was significantly increased at 0,1 , and 2 months in control adult rats as compared to untreated young control rats (Figure 6(d)). No significant change in the percentage of fat mass was observed in other groups of rats.

3.8. Measurement of Muscle Function by Open Field Test. No significant change was observed in total path and speed of movement of young, adult, and old rats as measured by the open field test (Figure 7).

3.9. Measurement of Muscle Function by Rotarod Test. No significant change was observed in the time of fall of young, adult, and old rats as measured by the rotarod test (Figure 8)

3.10. Analysis of Damaged DNA. Damaged DNA was measured by comet assay in old rats which is represented by tail length, tail moment, tail DNA percentage, and olive moment. The tail length, tail moment, and olive moment were significantly increased at 1 month but decreased at 2 and 3 months in old rats treated with ginger $(p<0.05)$ (Figure 9(a)). A similar increase was observed in tail DNA percentage at 1 month in old rats treated with ginger but decreased at 3 months of ginger treatment $(p<0.05)$.
3.11. Histological Observation. Histological examination of $\mathrm{H} \& \mathrm{E}$-stained cross sections of the quadriceps femoris muscle revealed polyhedral-shaped fibre with acidophilic sarcoplasm and peripherally located flat nuclei in both young and adult control groups and also in the gingertreated groups (Figures 10(a), 10(b), 10(d), and 10(e)). Each muscle fibre was surrounded by thin connective tissue of perimysium (Figure 10, arrow).

There was an apparent decrease in the size and number of the muscle fibres and fascicles in the old control group (Figure 10(c)). The shape of the muscle fibres appeared angulated and separated by a wide connective tissue endomysium. Dilated blood vessel was also seen in between the muscle fibres (Figure 10(c)). The perimysium separating the muscle fascicles was wide.

Old rats treated with ginger showed heterogenous morphology of polyhedral and angulated muscle fibres of various sizes (Figure 10(f)). The connective tissue of endomysium and perimysium appeared narrower in most areas compared to that of the old control group. In longitudinal section, cellular infiltration was observed between the muscle fibres of the old control group (Figure 11(c)) but was not apparent in the old gingertreated group (Figure 11(f)). Fat infiltration, disruption of muscle fibres, vacuole formation, and centrally located nuclei (evidence of regeneration) were not evident in all groups. 


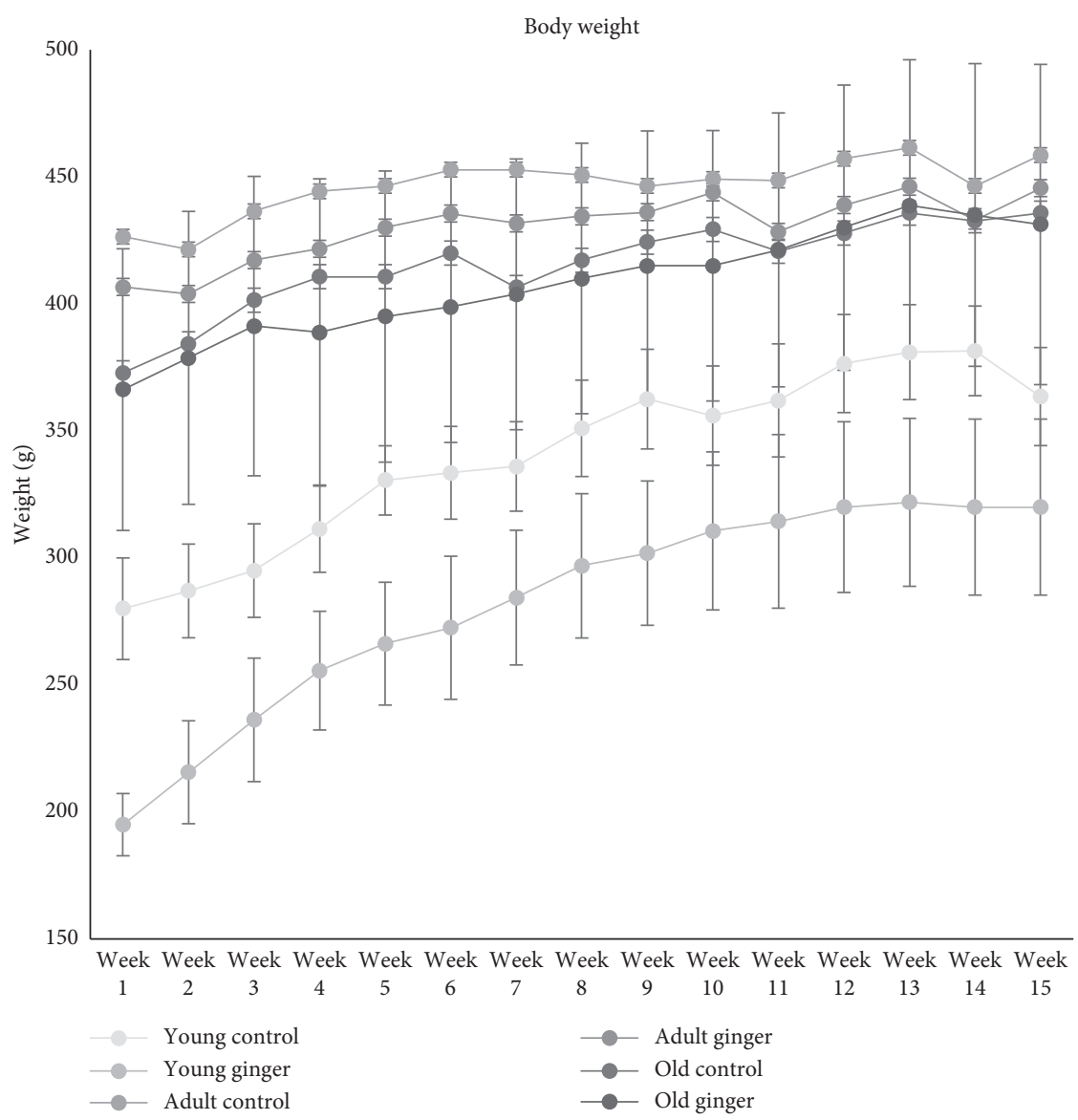

(a)

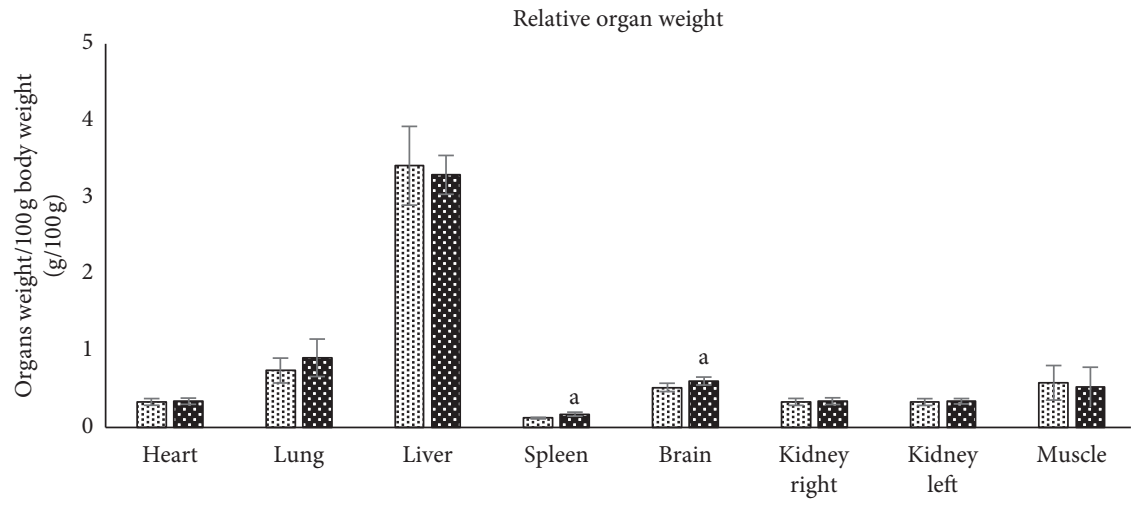

곡 Young control

. Young ginger

(b)

Figure 4: Continued. 


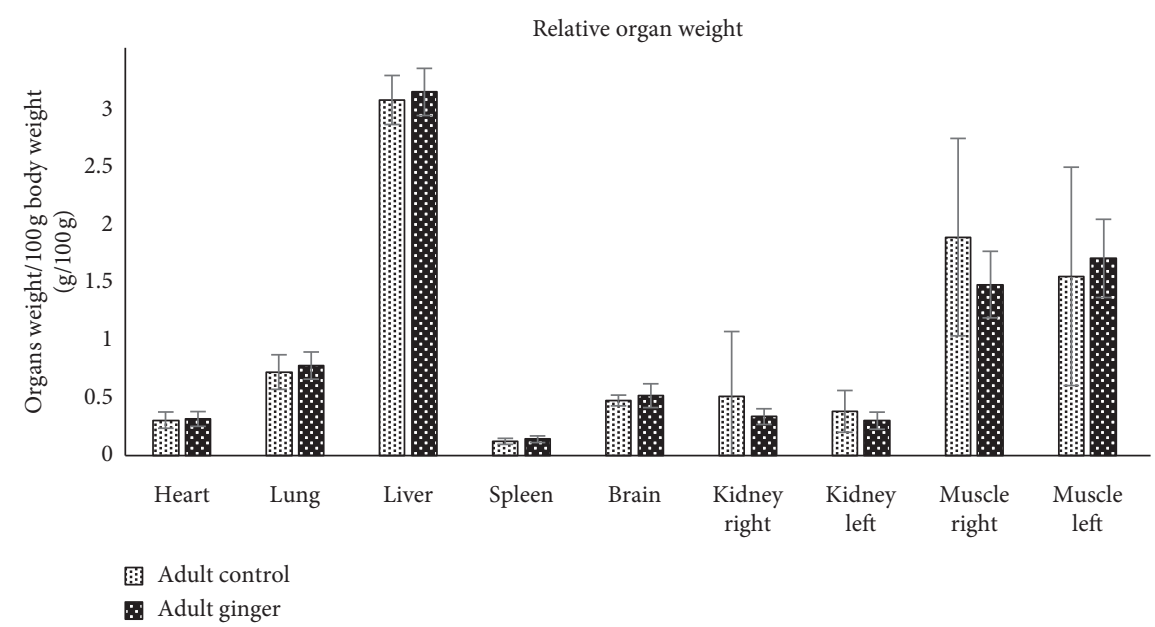

(c)

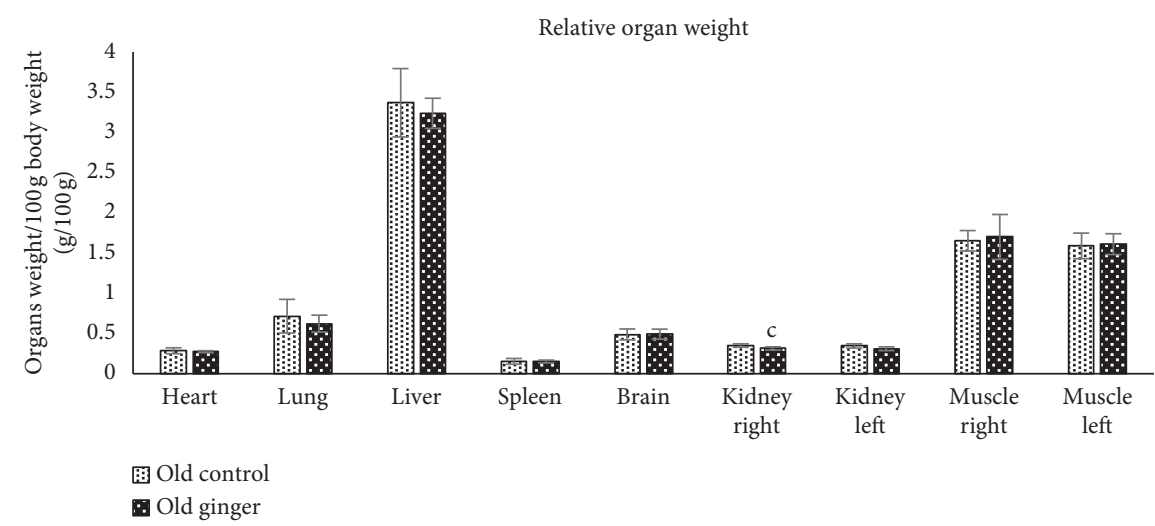

(d)

Figure 4: The (a) body weight and relative organ weight of (b) young, (c) adult, and (d) old rats. The data are presented as mean \pm SD ( $n=8$ (control rats); $n=10$ (Z. officinale-treated rats)). ${ }^{\mathrm{a}} p<0.05$, significantly different compared to control young rats; ${ }^{\mathrm{c}} p<0.05$, significantly different compared to control old rats, with a post hoc Bonferroni test.

\section{Discussion}

Sarcopenia is a geriatric syndrome that involves decline of muscle mass and strength which increases the risk of disability, mobility loss, and mortality [27]. One of the causes that contribute to the pathogenesis of sarcopenia is the presence of high level of oxidative stress in the body [28]. Generally, oxidative stress occurs when the production of ROS is higher as compared to the production of antioxidant. The overproduction of ROS could result in DNA damage and cell dysfunction which later might contribute to the deterioration of muscle mass and strength. Thus, in this study, we elucidated the effect of ginger (Z. officinale Roscoe) in improving muscle performance in SD rats. Three groups of male SD rats were used in this study which were 3-, 9-, and 21-month-old rats. These three groups of rats were treated either with ginger extract or distilled water. Muscle performance of rats was evaluated by measuring muscle strength, muscle function, and muscle and bone integrity while DNA damage was measured via comet assay and histological analysis by $\mathrm{H} \& \mathrm{E}$ staining.
Ginger has been extensively studied as antioxidant and anti-inflammatory agent in various types of diseases including diabetes, cardiovascular disease, hypertension, and others. Ginger extract has been proven to improve the expression of antioxidant enzyme as well as restore the level of glutathione in Alzheimer's disease [29]. Besides, ginger extract also exhibits a positive effect in osteoarthritis disease by decreasing the level of TNF- $\alpha$, IL- 8 , and hs-CRP [30, 31]. In type 2 diabetes, supplementation of powdered ginger capsule has attenuated the level of glucose, MDA, CRP, and insulin resistance together with the improvement of antioxidant capacity and serum paraoxonase-1 [32].

Our findings showed that the ginger extract used in this study did not cause any toxicity effect as no toxicity and mortality were observed in the pilot and toxicity studies. No change in BW was observed in this study. Gross pathological evaluations showed no signs of organs abnormalities on each organ of the pilot and toxicity studies. Generally, the ROW also showed no differences. The value of biochemical parameters of liver function test showed no differences in this study. This finding was in line with another study which reported that subchronic oral administration of ginger oil up 


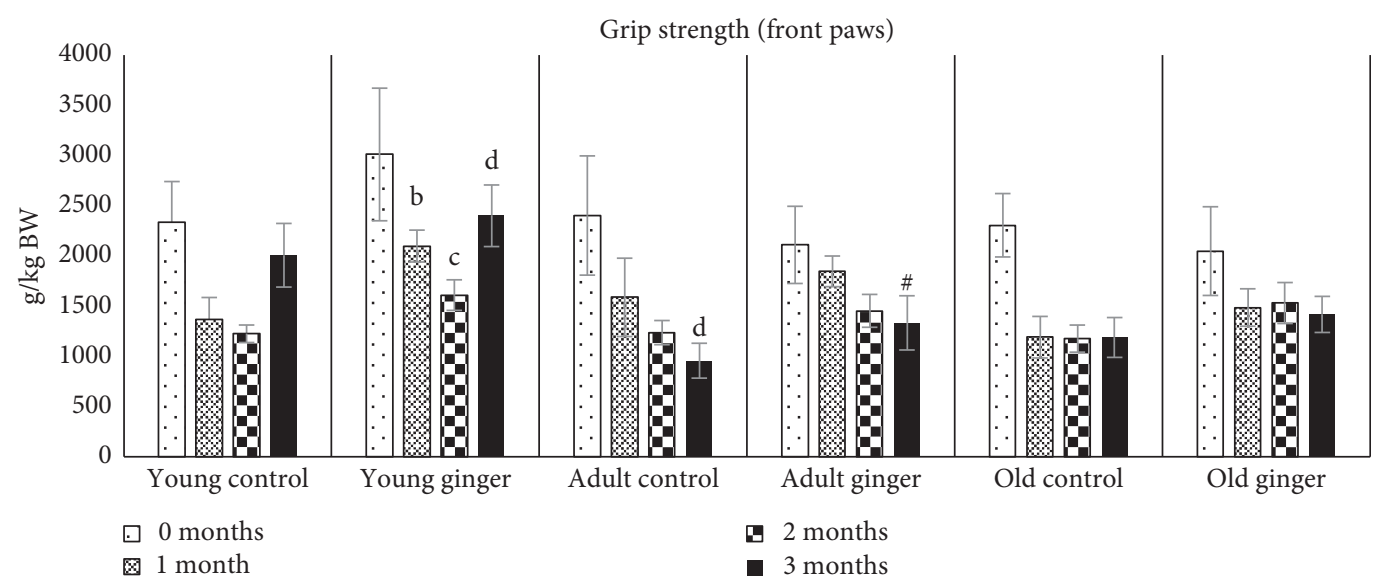

(a)

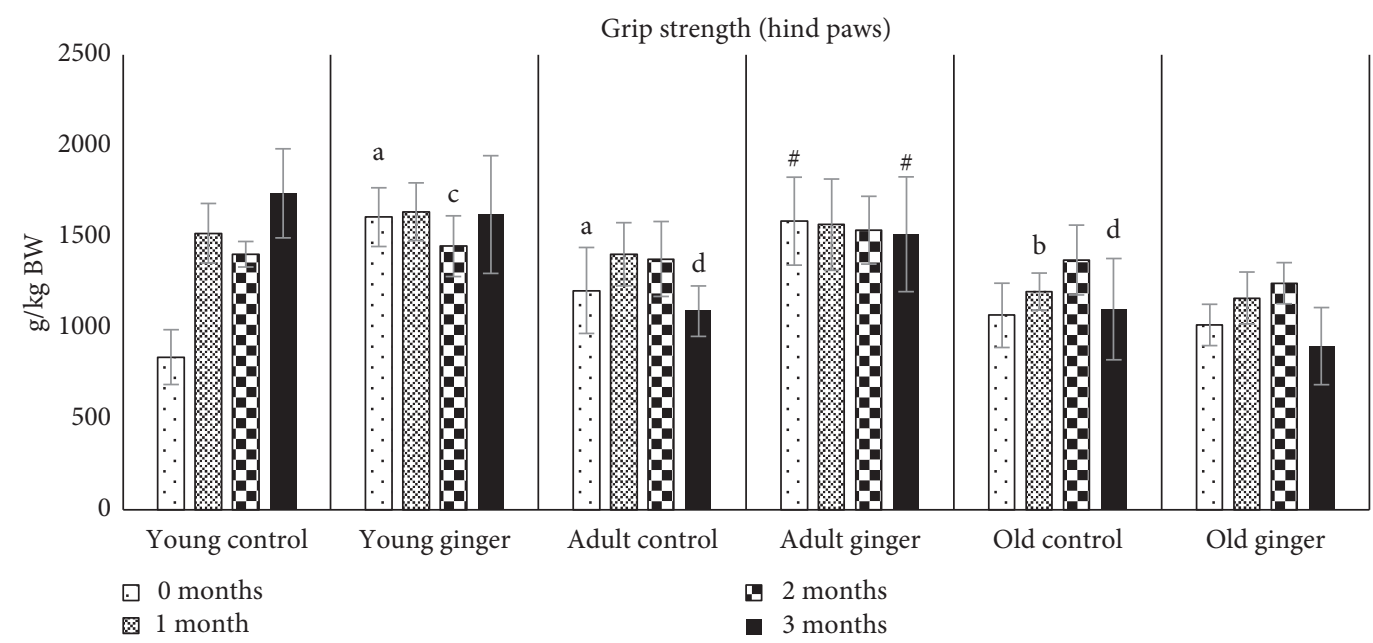

(b)

Figure 5: The grip strength of (a) front paws and (b) hind paws of young, adult, and old rats. The data are presented as mean \pm SD $(n=8$ (control rats); $n=10$ (Z. officinale-treated rats)). ${ }^{*} p<0.05$, significantly different compared to control young rats on respective month; ${ }^{\#} p<0.05$ significantly different compared to control adult rats on respective month; ${ }^{a} p<0.05$, significantly different compared to control young rats at 0 months; ${ }^{\mathrm{b}} p<0.05$, significantly different compared to control young rats at 1 month; ${ }^{\mathrm{c}} p<0.05$, significantly different compared to control young rats on at 2 months; ${ }^{\mathrm{d}} p<0.05$, significantly different compared to control young rats on at 3 months, with a post hoc Bonferroni test.

to $500 \mathrm{mg} / \mathrm{kg}$ per day did not show any toxic effect to Wistar rats in terms of hematological parameters, renal parameters, and histopathological parameters of kidney [33]. Conversely, another toxicity study of 60-day subchronic ginger supplementation reported that $10 \mathrm{~mL} / \mathrm{kg}$ of ginger fixed oil induced oxidative stress, cellular toxicities, and organ' toxicities in kidneys, liver, spleen, and lungs [34].

In this study, muscle strength was determined by the grip strength test while muscle function was assessed by the open field test and rotarod test. Our findings showed that muscle strength was decreased with increasing age of the rats. Treatment with ginger extract for 3 months was able to increase the grip strength of young rats as early as 1 month after treatment. However, no similar effect was observed in adult and old rats treated with ginger. This could be due to the higher muscle regenerative capacity of the young gingertreated rats than adult or old ginger-treated rats. The muscle regenerative capacity totally depends on the regeneration of satellite cells which slowly decreased with ageing [35]. It has been reported that the number of satellite cells decreased as ageing occurs [36]. A study conducted by Khor et al. [37] reported that senescent myoblast has low proliferative capacity, which showed downregulation of myogenic differentiation genes, but the expression of oxidative damageassociated gene was increased which may contribute to the decreased muscle regenerative capacity of adult and old ginger-treated rats observed in this study.

The findings on muscle strength in this study could also be due to the accumulation of ROS in adult and old gingertreated rats which was higher than young ginger-treated rats. This is because with the advancing of age, there is overproduction of ROS in the body and the capacity to remove it from the body was decreased [38]. A previous study reported that the accumulation of ROS in senescent myoblast could contribute to the modifications in the cell membrane, extracellular matrix (ECM), and cytoskeleton by altering 


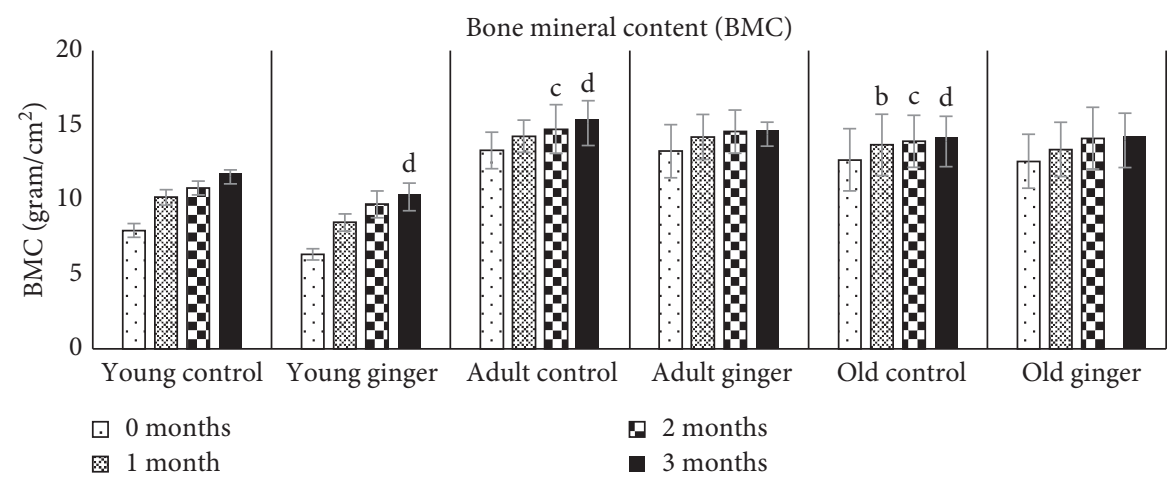

(a)

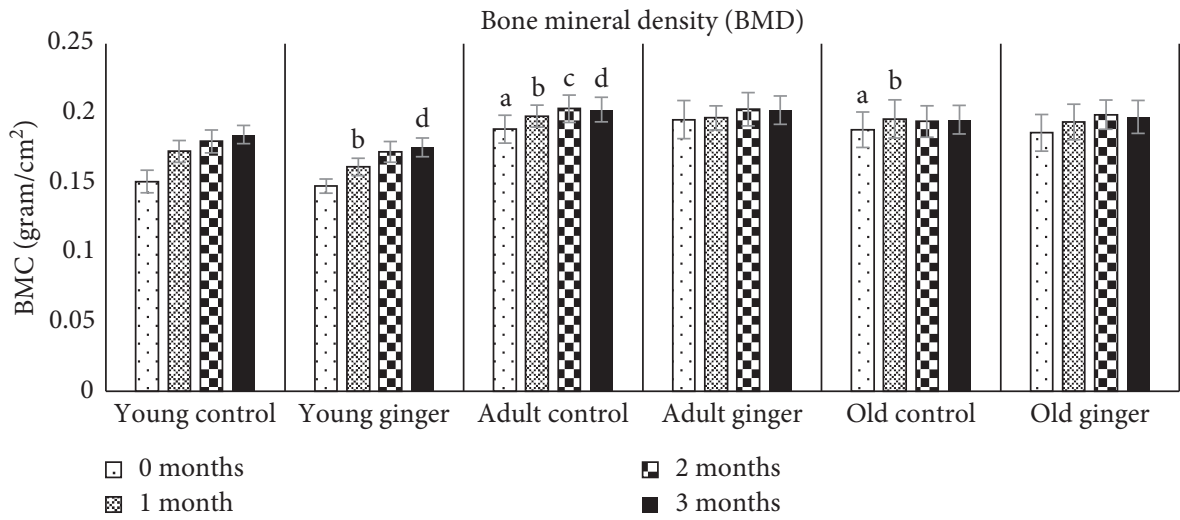

(b)

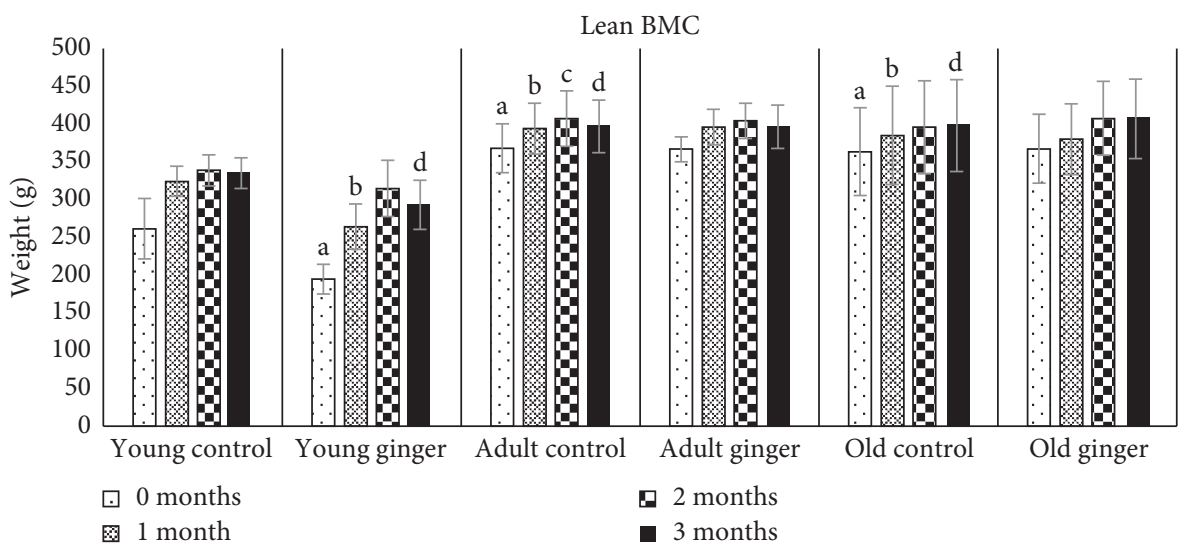

(c)

FIgURE 6: Continued. 


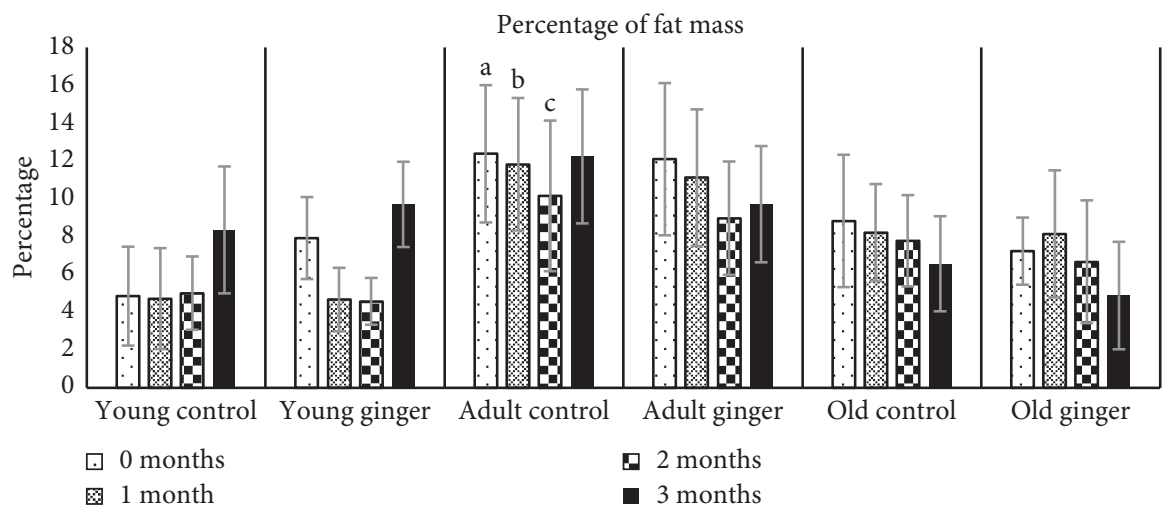

(d)

Figure 6: The (a) bone mineral content (BMC), (b) bone mineral density (BMD), (c) lean BMC, and (d) percentage of fat mass of young, adult, and old rats. Data are presented as mean \pm SD $\left(n=8\right.$ (control rats); $n=10$ (Z. officinale-treated rats)). ${ }^{\mathrm{a}} p<0.05$, significantly different compared to control young rats at 0 months; ${ }^{\mathrm{b}} p<0.05$, significantly different compared to control young rats at 1 month; ${ }^{\mathrm{c}} p<0.05$, significantly different compared to control young rats at 2 months; ${ }^{\mathrm{d}} p<0.05$, significantly different compared to control young rats at 3 months, with a post hoc Bonferroni test.

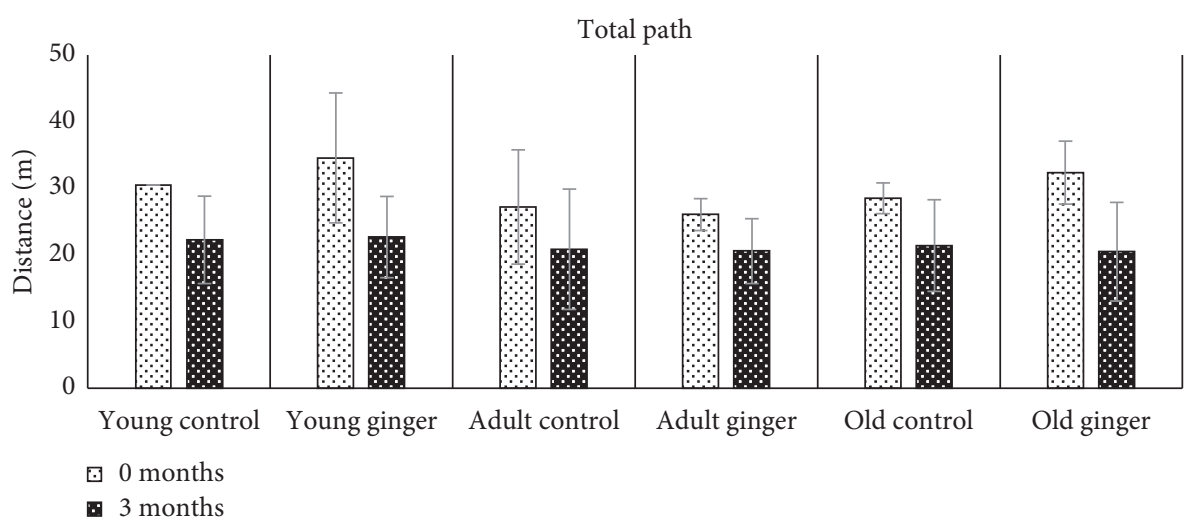

(a)

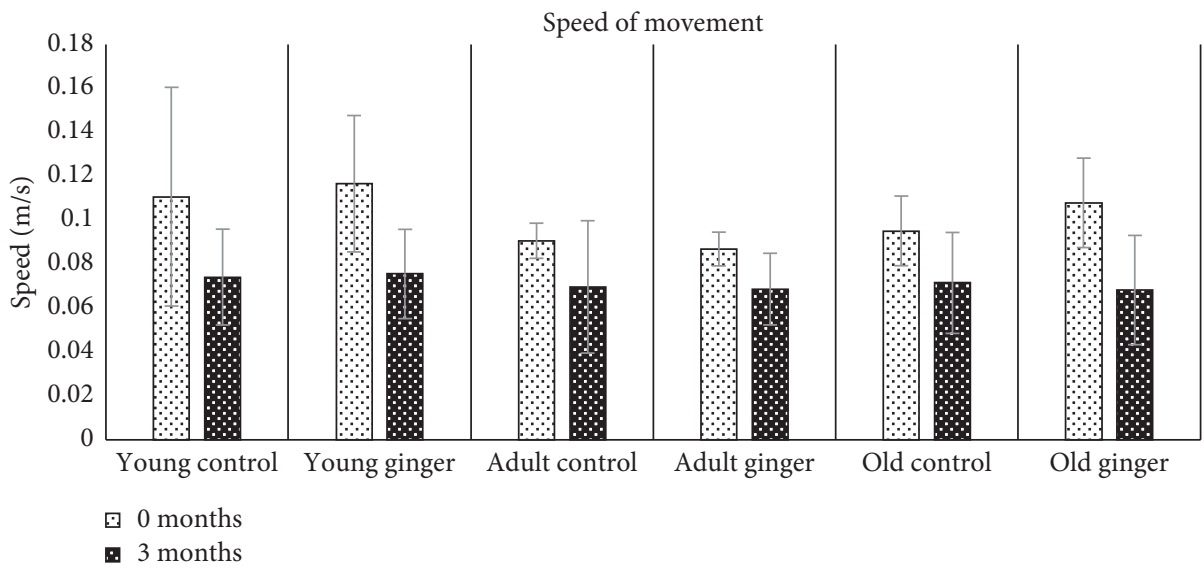

(b)

Figure 7: The (a) total path and (b) speed of movement of young, adult, and old rats. Data are presented as mean \pm SD ( $n=8$ (control rats); $n=10$ (Z. officinale-treated rats)). No significant changes were found.

cellular metabolism and pathway [39]. These cell structures are essential in maintaining the integrity of myoblast cell structure.
Moreover, accumulation of ROS could lead to the content reduction of myosin protein as well as inhibit the occurrence of transcriptional process of myostatin gene 


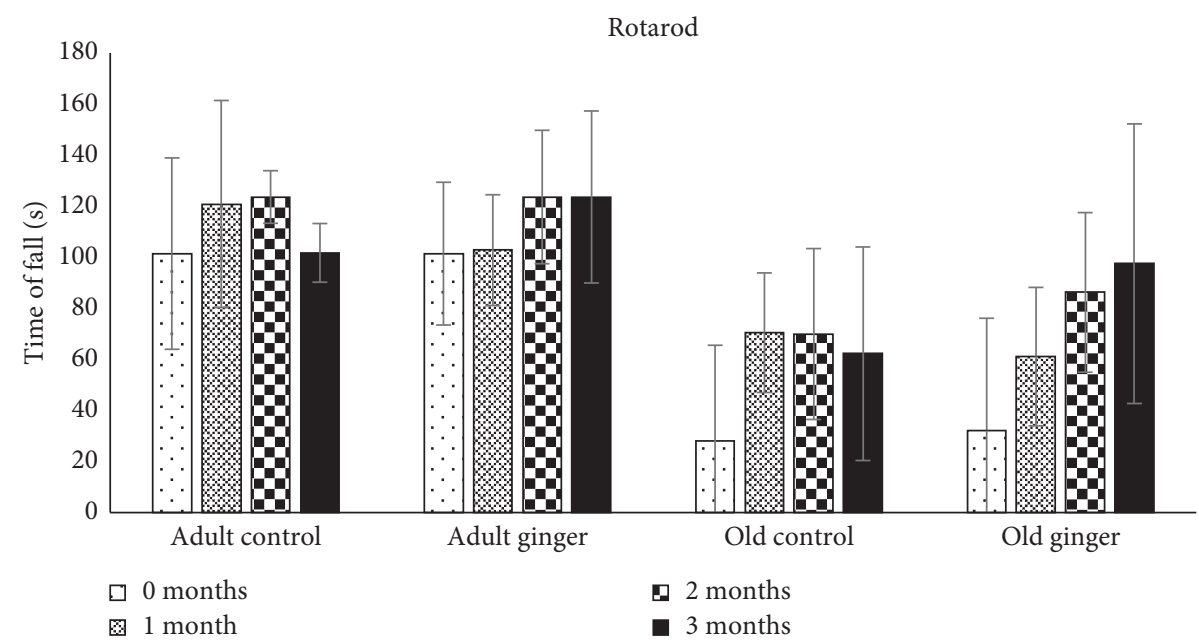

FIGURE 8: The rotarod performance test of young, adult, and old rats. Data are presented as mean \pm SD ( $n=8$ (control rats); $n=10$ ( $Z$. officinale-treated rats)). No significant change was observed.

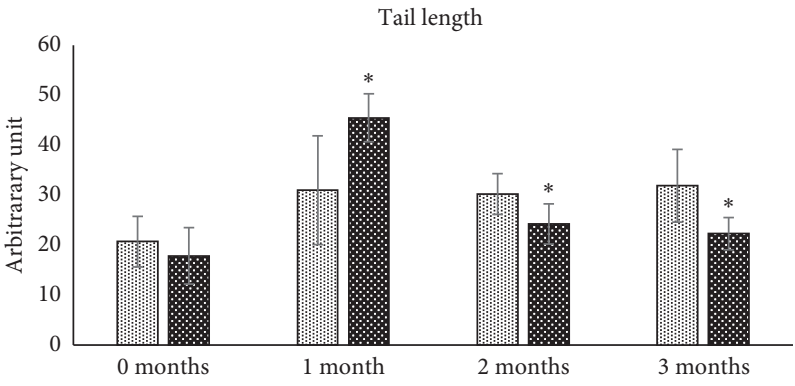

Ð Old control

Old ginger

(a)

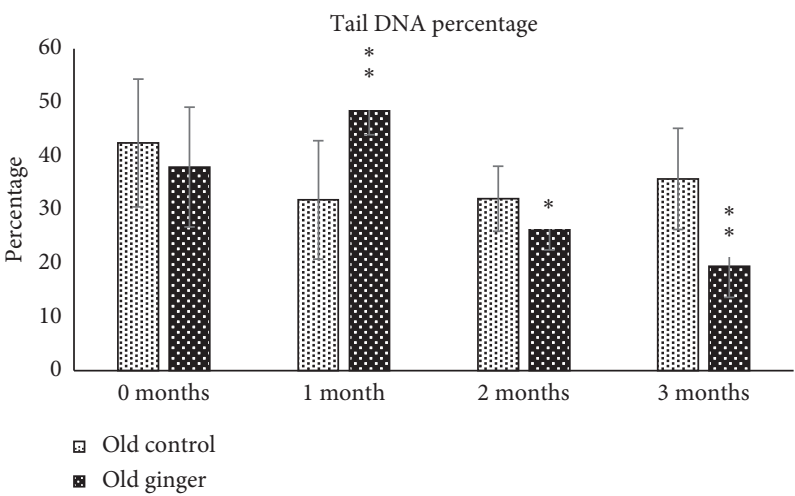

(c)

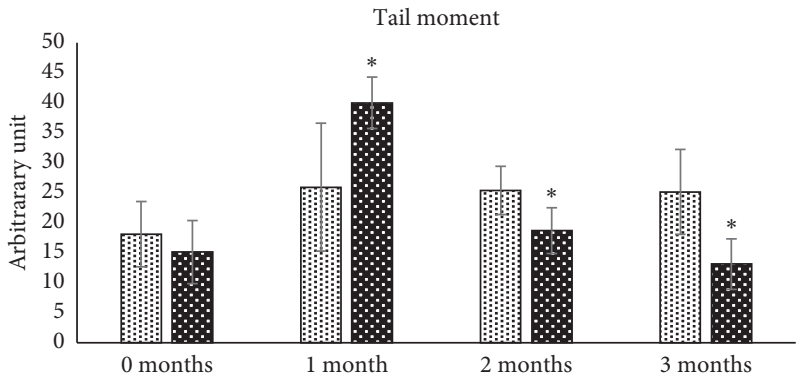

田 Old control

Old ginger

(b)

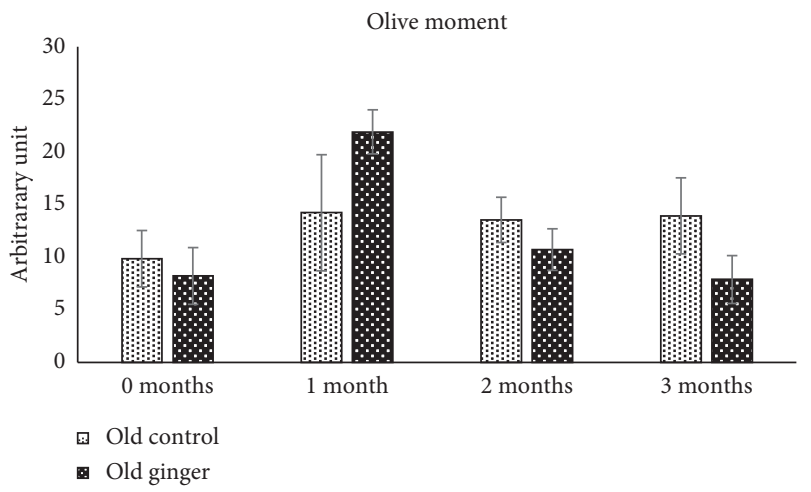

(d)

FIGURE 9: The level of damaged DNA of old rats was measured based on (a) tail length, (b) tail moment, (c) tail DNA percentage, and (d) olive moment using the comet assay method. Data are presented as mean \pm SD $(n=8$ (control rats); $n=10$ (Z. officinale-treated rats)). ${ }^{*} p<0.05$, significantly different compared to control old rats with a post hoc Bonferroni test.

resulting in imbalanced protein synthesis and protein breakdown [40, 41]. The deterioration of myosin expression also caused dysfunction of myofilament which later can affect the muscle performance [41]. Besides, the presence of ROS in the body will result in decreased production of acetylcholine in synaptic cleft that contributes to the failure of action potential production by sarcolemma as well as affects the neuromuscular junction which is essential in preserving muscle strength and quality $[42,43]$. The continuous production of ROS also contributes to changing the morphology of neuromuscular junction and reducing the number of fibre and innervation [44]. 


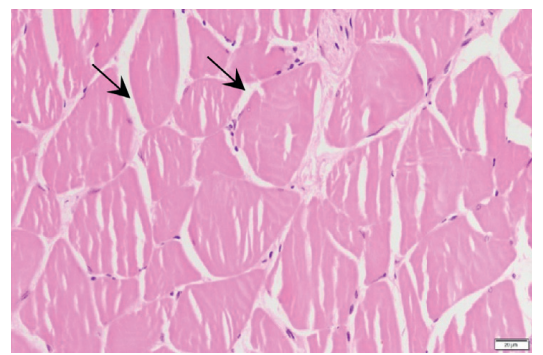

(a)

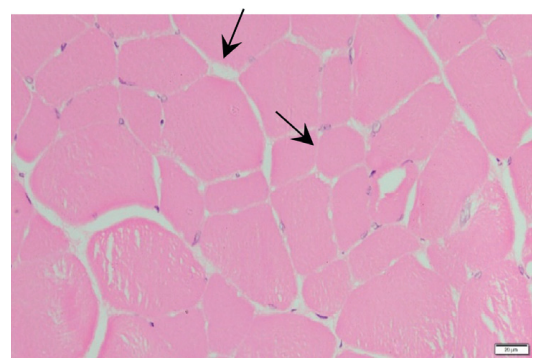

(d)

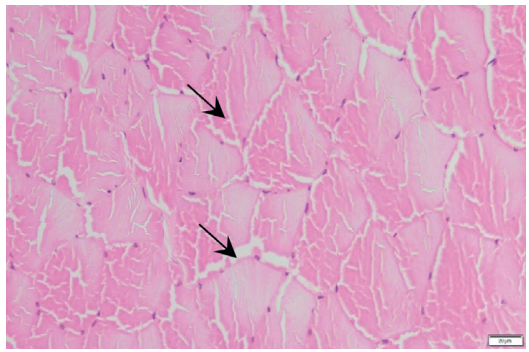

(b)

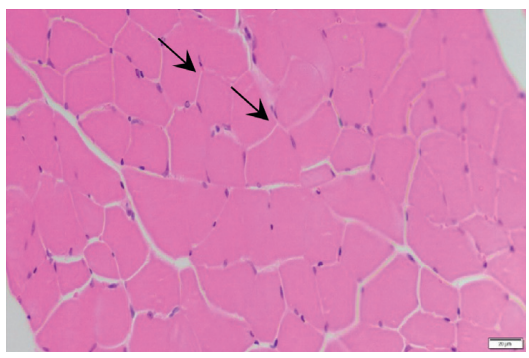

(e)

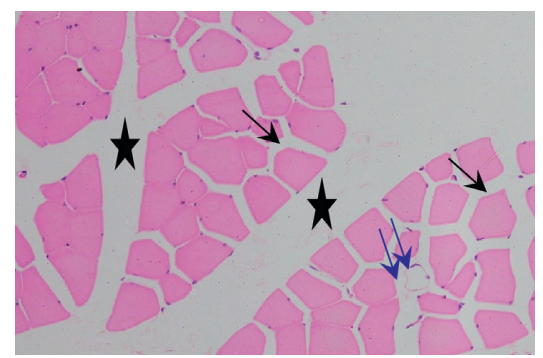

(c)

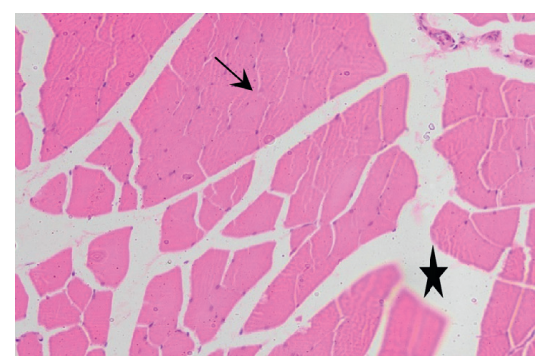

(f)

FIGURE 10: Cross section of H\&E-stained rat muscle fibres and fascicles of the quadriceps femoris muscle. Rats treated with distilled water: (a) young, (b) adult, and (c) old control groups. Rats treated with Z. officinale: (d) young-, (e) adult-, and (f) old-treated groups. Each muscle fibre was surrounded by epimysium (black arrow), and the muscle fascicle was surrounded by abundant connective tissue ( $\star$ ). Dilated blood vessel is shown by blue double arrows. Images were photographed at 400x magnification.

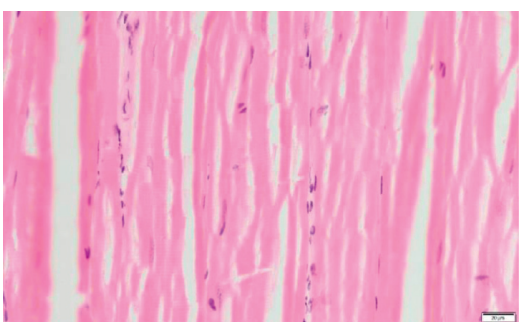

(a)

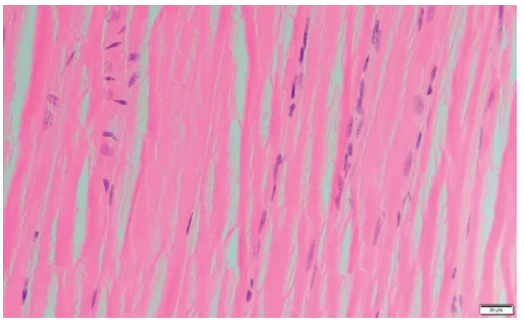

(d)

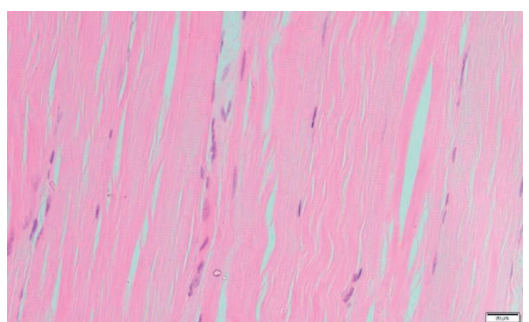

(b)

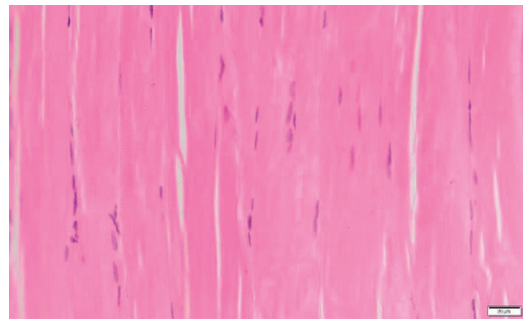

(e)

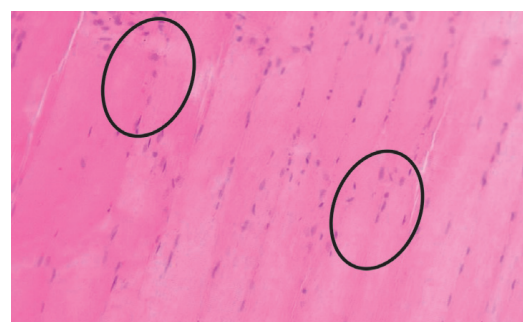

(c)

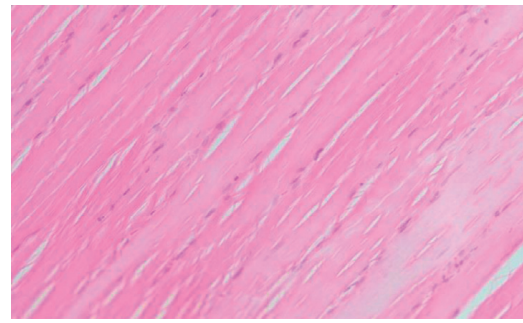

(f)

Figure 11: Longitudinal section of H\&E-stained rat muscle fibres and fascicles of the quadriceps femoris muscle. Rats treated with distilled water: (a) young, (b) adult, and (c) old control groups. Rats treated with Z. officinale: (d) young-, (e) adult-, and (f) old-treated groups. Many nuclei are seen infiltrating the muscle fibres (oval area). Images were photographed at 400x magnification.

In this study, muscle and bone integrity were determined by measuring bone mineral density (BMD), bone mineral content (BMC), and fat free mass (FFM). The results of the present study showed that BMC, BMD, lean BMC, and FFM were increased with increasing age of the rats. Treatment with ginger for three months did not cause any significant effect to all parameters measured in all groups of rats. However, in young rats, ginger treatment caused a reduction in $\mathrm{BMC}, \mathrm{BMD}$, and lean BMC. These observations could be due to short-term supplementation of ginger extract in the treated group of rats. $\mathrm{BMD}, \mathrm{BMC}$, and lean $\mathrm{BMC}$ are major determinants of bone strength since they are involved in bone structure process. As ageing occurs, there is abundant generation of ROS with insufficient support of antioxidant system which later gives a negative effect towards osteoblast and osteoclast regulation [45]. The accumulation of 
oxidative stress during ageing could affect the bone turnover by triggering imbalance production of cells responsible for bone resorption and formation [46]. A previous study has proven that dietary compounds with enriched antioxidant and anti-inflammatory properties have promising bone protective effects. A study conducted by Varela-López et al. displayed that $\mathrm{CoQ}_{10}$ supplementation could contribute to the lowest loss of BMD in aged rats by preventing DNA and lipid damage [47]. In another study, they found that intake of dried plum that consists of enriched antioxidant properties could improve alkaline phosphatase activity, insulinlike growth factor-1 (IGF-1), and BMD in postmenopausal women by suppressing the rate of bone turnover [48]. Moreover, blueberry supplementation in rats improved the bone formation rate, osteoblast number, and levels of trabecular bone volume together with inhibition of osteoblast senescence and bone loss [49]. Hence, long-term supplementation of ginger extract may exhibit a similar effect as other antioxidant dietary compounds in improving BMC, $\mathrm{BMD}$, and lean BMC in aged rats.

The findings of this study also showed that treatment of ginger for 3 months to the old rats was able to decrease the level of damaged DNA. This indicates the potential of ginger in alleviating DNA damage caused by overproduction of ROS. This finding was in line with current result which found that treatment with ginger significantly increased the grip strength of front and hind paws of young and adult rats as compared to untreated control. The potential of ginger as antioxidant agent in decreasing the level of ROS has been reported in previous findings. A study conducted by Tung et al. found that ginger root extract has shown antioxidant and acetylcholinesterase inhibitory activity in Alzheimer's disease [50]. This was supported by another finding which reported that 6-gingerol in ginger extract has the ability to increase the expression of antioxidant enzyme as well as restore glutathione level [29]. The antioxidant properties of ginger have also been reported in a study carried out by Fahmi et al. [51] which found that ginger extract was able to lessen the severity of diethylnitrosamine (DEN) toxicity in rats by increasing the level of serum high-density lipoprotein (HDL) and plasma glutathione peroxidase (GSH-Px) activity, accompanied by decreased low-density lipoprotein (LDL), serum alanine aminotransferase (ALT), and alkaline phosphatase (ALP). In another study, ginger has been proven to attenuate lipid peroxidation with reduction of MDA level and increase glutathione S-transferase activity in the liver of Wistar rats [52]. There was also significant reduction in body weight and lipid droplet deposition in the rats' liver.

Histological analysis carried out in this study showed that sarcopenia is evident in the muscle of old rats but it is still in the early stage. Apparent reduction in the size of muscle fibre and fascicles with heterogenous morphology of the muscle fibres and mild sequestration of cellular infiltration were observed. However, the full-blown sarcopenic histological findings such as fat infiltration, mononuclear infiltration, disruption of muscle fibre arrangement, and vacuole formation were absent. These sarcopenic changes, however, were lesser in old rats treated with ginger extract even though there was evidence of cellular infiltration (mild inflammation) and dilated blood vessels. The sarcopenic changes observed in old rats in this study were milder as compared to another study which showed that muscle fibres of diabetic rats treated with Centella asiatica have increased in size, appeared in closely space, and become more continuous as well as the muscle fibres have been restored in regular polygonal shape [53]. However, this result was similar with a previous study which found that treatment with mixed Japanese herbs known as "Dokhwalgisaengtang" on disuse muscle atrophy rats has decreased the myofibre size of the gastrocnemius muscle [54]. The accumulation of nuclei around the myofibres was also observed indicating the presence of inflammatory cells. The lesser sarcopenic changes in old rats treated with ginger observed in this study may indicate the ameliorative action of ginger as antioxidant agent by enhancing structural protein synthesis. This is because the production of excessive ROS in skeletal muscle could cause sarcopenia leading to deleterious structural changes by affecting the muscle fibres lipid membrane bilayer [55]. Furthermore, the presence of excess ROS will cause imbalance between protein synthesis and degradation which later contributes to the reduction in skeletal muscle fibres [56].

The molecular finding from this study was limited as it focused on the outcome of ginger supplementation on muscle performance. Therefore, further study is needed to elucidate the molecular mechanism of ginger in improving muscle performance. By performing a molecular study, the exact mechanism of ginger in reducing the level of oxidative stress in the muscle can be confirmed which can be used as a preventative measure for muscle disease, such as sarcopenia. However, the improvement of muscle performance in SD rats supported by the histological findings and the reduction of DNA damage observed in the present study strengthen the properties of ginger as an antioxidant agent, and thus it can be potentially used to alleviate oxidative stress and prevent age-related muscle disease.

\section{Conclusions}

In conclusion, ginger or Zingiber officinale Roscoe prevents DNA damage and improves muscle performance and bone integrity in Sprague Dawley rats indicating its potential in alleviating oxidative stress in ageing and thus delaying sarcopenia progression.

\section{Abbreviations}

SPSS: $\quad$ Statistical Package for the Social Sciences

ANOVA: Analysis of variance

SD: $\quad$ Standard deviation

BW: Body weight

ROW: Relative organ weight

BBM: Bold's basal media

DXA: Dual energy X-ray absorptiometry

BMC: Bone mineral content

BMD: Bone mineral density

CKMM: Creatine kinase-MM 
MDA: Malondialdehyde

HAE: 4-Hydroxyalkenals

HRP: Horseradish peroxidase

TMB: $\quad 3,3^{\prime}, 5,5^{\prime}$-Tetramethylbenzidine

PBS: $\quad$ Phosphate buffer saline

BHT: $\quad$ Butylated hydroxytoluene

ROS: $\quad$ Reactive oxygen species

RNS: Reactive nitrogen species.

\section{Data Availability}

The data supporting the conclusion of this article are included within the article.

\section{Ethical Approval}

The research has been approved by the Universiti Kebangsaan Malaysia Animal Ethics Committee (UKMAEC Approval Number: BIOK/PP/2018/SUZANA/14-MAY/924JUNE-2018-MAY-2020).

\section{Disclosure}

The funding bodies from this research did not have any role in the design of the study, collection, analysis, and interpretation of data, and in writing the manuscript.

\section{Conflicts of Interest}

The authors declare that they have no conflicts of interest.

\section{Authors' Contributions}

SM contributed to the experimental design, supervised the work, interpreted the data, and drafted, revised, and corrected the manuscript for publication. NFNMS drafted the manuscript and NFAS performed the experimentation, analyzed the data, and drafted the manuscript while $\mathrm{NHH}$, NAR, SNAZ, and AFAR performed the experimentation. JKT, NAG, and MFMN were involved in data analysis and interpretation. All authors read and approved the final manuscript.

\section{Acknowledgments}

The authors are thankful for the contribution from all the researchers and staff of the Department of Biochemistry, Faculty of Medicine, Universiti Kebangsaan Malaysia Medical Centre. This research was supported by Universiti Kebangsaan Malaysia (UKM) Dana Cabaran Perdana Research Grant with project code: AP-2017-009/3.

\section{References}

[1] J. D. Walston, "Sarcopenia in older adults," Current Opinion in Rheumatology, vol. 24, no. 6, pp. 623-627, 2012.

[2] J. E. Morley, "Undernutrition in older adults," Family Practice, vol. 29, no. 1, pp. i89-i93, 2012.

[3] M. Yamada, S. Nishiguchi, N. Fukutani et al., "Prevalence of sarcopenia in community-dwelling Japanese older adults,"
Journal of the American Medical Directors Association, vol. 14, no. 12, pp. 911-915, 2013.

[4] A. J. Cruz-Jentoft, J. P. Baeyens, J. M. Bauer et al., "Sarcopenia: European consensus on definition and diagnosis: report of the European working group on sarcopenia in older people," Age and Ageing, vol. 39, no. 4, pp. 412-423, 2010.

[5] O. Rom, S. Kaisari, D. Aizenbud, and A. Z. Reznick, "Lifestyle and sarcopenia-etiology, prevention, and treatment," Rambam Maimonides Medical Journal, vol. 3, no. 4, 2012.

[6] S. Fulle, F. Protasi, G. Di Tano et al., "The contribution of reactive oxygen species to sarcopenia and muscle ageing," Experimental Gerontology, vol. 39, no. 1, pp. 17-24, 2004.

[7] S. Palipoch and P. Koomhin, "Oxidative stress-associated pathology: a review," Sains Malaysiana, vol. 44, no. 10, pp. 1441-1451, 2015.

[8] A. Phaniendra, D. B. Jestadi, and L. Periyasamy, "Free radicals: properties, sources, targets, and their implication in various diseases," Indian Journal of Clinical Biochemistry, vol. 30, no. 1, pp. 11-26, 2015.

[9] S. Suzuki, N. Fujita, N. Hosogane et al., "Excessive reactive oxygen species are therapeutic targets for intervertebral disc degeneration," Arthritis Research \& Therapy, vol. 17, no. 1, p. 316, 2015.

[10] N. Khansari, Y. Shakiba, and M. Mahmoudi, "Chronic inflammation and oxidative stress as a major cause of age-related diseases and cancer," Recent Patents on Inflammation \& Allergy Drug Discovery, vol. 3, no. 1, pp. 73-80, 2009.

[11] A. Ayala, M. F. Muñoz, and S. Argüelles, "Lipid peroxidation: production, metabolism, and signaling mechanisms of malondialdehyde and 4-hydroxy-2-nonenal," Oxidative Medicine and Cellular Longevity, vol. 2014, Article ID 360438, 31 pages, 2014.

[12] R. Koopman and L. J. C. van Loon, "Aging, exercise, and muscle protein metabolism," Journal of Applied Physiology, vol. 106, no. 6, pp. 2040-2048, 2009.

[13] N. Noran, A. Bulgiba, T. Guat, and I. Mudl, "Sarcopenia in older people," Geriatrics, InTech, Shanghai, China, pp. 29-40, 2012.

[14] C. D. McMahon, R. Chai, H. G. Radley-Crabb et al., "Lifelong exercise and locally produced insulin-like growth factor-1 (IGF-1) have a modest influence on reducing age-related muscle wasting in mice," Scandinavian Journal of Medicine \& Science in Sports, vol. 24, no. 6, pp. e423-e435, 2014.

[15] C. Vigorito and F. Giallauria, "Effects of exercise on cardiovascular performance in the elderly," Frontiers in Physiology, vol. 5, p. 51, 2014.

[16] K. Tanaka, M. Arita, H. Sakurai, N. Ono, and Y. Tezuka, "Analysis of chemical properties of edible and medicinal ginger by metabolomics approach," BioMed Research International, vol. 2015, Article ID 671058, 7 pages, 2015.

[17] M. Park, J. Bae, and D.-S. Lee, "Antibacterial activity of [10]gingerol and [12]-gingerol isolated from ginger rhizome against periodontal bacteria," Phytotherapy Research, vol. 22, no. 11, pp. 1446-1449, 2008.

[18] R. B. van Breemen, Y. Tao, and W. Li, "Cyclooxygenase-2 inhibitors in ginger (Zingiber officinale)," Fitoterapia, vol. 82, no. 1, pp. 38-43, 2011.

[19] A. J. Akinyemi, A. O. Ademiluyi, and G. Oboh, "Inhibition of angiotensin-1-converting enzyme activity by two varieties of ginger (Zingiber officinale) in rats fed a high cholesterol diet," Journal of Medicinal Food, vol. 17, no. 3, pp. 317-323, 2014.

[20] A. J. Akinyemi, G. Oboh, A. O. Ademiluyi, A. A. Boligon, and M. L. Athayde, "Effect of two ginger varieties on arginase activity in hypercholesterolemic rats," Journal of Acupuncture and Meridian Studies, vol. 9, no. 2, pp. 80-87, 2016. 
[21] S. Wang, M. Tian, R. Yang et al., "6-gingerol ameliorates behavioral changes and atherosclerotic lesions in ApoE-/mice exposed to chronic mild stress," Cardiovascular Toxicology, vol. 18, no. 5, pp. 420-430, 2018.

[22] G. Park, H. G. Kim, M. S. Ju et al., "6-shogaol, an active compound of ginger, protects dopaminergic neurons in Parkinson's disease models via anti-neuroinflammation," Acta Pharmacologica Sinica, vol. 34, no. 9, pp. 1131-1139, 2013.

[23] S. K. Ha, E. Moon, M. S. Ju et al., "6-shogaol, a ginger product, modulates neuroinflammation: a new approach to neuroprotection," Neuropharmacology, vol. 63, no. 2, pp. 211-223, 2012.

[24] M. Sarip, Subcritical Water Extraction of 6-gingerol and 6shogaol from Zingiber Officinale, Universiti Teknologi Malaysia, Skudai, Malaysia, 2012.

[25] N. F. Sani, L. K. Belani, C. P. Sin et al., "Effect of the combination of gelam honey and ginger on oxidative stress and metabolic profile in streptozotocin-induced diabetic SpragueDawley rats," BioMed Research International, vol. 2014, Article ID 160695, 9 pages, 2014.

[26] N. P. Singh, M. T. McCoy, R. R. Tice, and E. L. Schneider, "A simple technique for quantitation of low levels of DNA damage in individual cells," Experimental Cell Research, vol. 175, no. 1, pp. 184-191, 1988.

[27] T. Lang, T. Streeper, P. Cawthon, K. Baldwin, D. R. Taaffe, and T. B. Harris, "Sarcopenia: etiology, clinical consequences, intervention, and assessment," Osteoporosis International, vol. 21, no. 4, pp. 543-559, 2010.

[28] T. Brioche and S. Lemoine-Morel, "Oxidative stress, sarcopenia, antioxidant strategies and exercise: molecular aspects," Current Pharmaceutical Design, vol. 22, no. 18, pp. 2664-2678, 2016.

[29] C. Lee, G. H. Park, C.-Y. Kim, and J.-H. Jang, "[6]-gingerol attenuates $\beta$-amyloid-induced oxidative cell death via fortifying cellular antioxidant defense system," Food and Chemical Toxicology, vol. 49, no. 6, pp. 1261-1269, 2011.

[30] H. Mozaffari-Khosravi, Z. Naderi, A. Dehghan, A. Nadjarzadeh, and H. Fallah Huseini, "Effect of ginger supplementation on proinflammatory cytokines in older patients with osteoarthritis: outcomes of a randomized controlled clinical trial," Journal of Nutrition in Gerontology and Geriatrics, vol. 35, no. 3, pp. 209-218, 2016.

[31] Z. Naderi, H. Mozaffari-Khosravi, A. Dehghan, A. Nadjarzadeh, and H. F. Huseini, "Effect of ginger powder supplementation on nitric oxide and C-reactive protein in elderly knee osteoarthritis patients: a 12 -week double-blind randomized placebo-controlled clinical trial," Journal of Traditional and Complementary Medicine, vol. 6, no. 3, pp. 199-203, 2016.

[32] F. Shidfar, A. Rajab, T. Rahideh, N. Khandouzi, S. Hosseini, and S. Shidfar, "The effect of ginger (Zingiber officinale) on glycemic markers in patients with type 2 diabetes," Journal of Complementary and Integrative Medicine, vol. 12, no. 2, pp. 165-170, 2015.

[33] K. Jeena, V. B. Liju, and R. Kuttan, “A preliminary 13-week oral toxicity study of ginger oil in male and female Wistar rats," International Journal of Toxicology, vol. 30, no. 6, pp. 662-670, 2011.

[34] E. O. Idang, O. K. Yemitan, H. O. Mbagwu, G. J. Udom, E. O. Ogbuagu, and J. A. Udobang, "Toxicological assessment of ZIngiber officinale Roscoe (Ginger) root oil extracts in Albino rats," Toxicology Digest, vol. 4, no. 1, pp. 108-119, 2019.
[35] N. A. Dumont, "Satellite cells and skeletal muscle regeneration," Comprehensive Physiology, vol. 5, no. 3, pp. 1027-1059, 2011.

[36] N. Miljkovic, J.-Y. Lim, I. Miljkovic, and W. R. Frontera, "Aging of skeletal muscle fibers," Annals of Rehabilitation Medicine, vol. 39, no. 2, p. 155, 2015.

[37] S. C. Khor, A. M. Razak, W. Z. W. Ngah, Y. A. M. Yusof, N. A. Karim, and S. Makpol, "The tocotrienol-rich fraction is superior to tocopherol in promoting myogenic differentiation in the prevention of replicative senescence of myoblasts," PLoS One, vol. 11, no. 2, 2016.

[38] I. Liguori, G. Russo, F. Curcio et al., "Oxidative stress, aging, and diseases," Clinical Interventions in Aging, vol. 13, pp. 757-772, 2018.

[39] X. Huang, L. Chen, W. Liu et al., "Involvement of oxidative stress and cytoskeletal disruption in microcystin-induced apoptosis in CIK cells," Aquatic Toxicology, vol. 165, pp. 4150, 2015.

[40] G. Musumeci, R. Imbesi, M. A. Szychlinska, and P. Castrogiovanni, "Apoptosis and skeletal muscle in aging," Open Journal of Apoptosis, vol. 4, no. 2, pp. 41-46, 2015.

[41] W. R. Frontera and J. Ochala, "Skeletal muscle: a brief review of structure and function," Calcified Tissue International, vol. 96, no. 3, pp. 183-195, 2015.

[42] C. W. Baumann, D. Kwak, H. M. Liu, and L. V. Thompson, "Age-induced oxidative stress: how does it influence skeletal muscle quantity and quality?" Journal of Applied Physiology, vol. 121, no. 5, pp. 1047-1052, 2016.

[43] M. Gonzalez-Freire, R. de Cabo, S. A. Studenski, and L. Ferrucci, "The neuromuscular junction: aging at the crossroad between nerves and muscle," Frontiers in Aging Neuroscience, vol. 6, p. 208, 2014.

[44] N. Pollock, C. A. Staunton, A. Vasilaki, A. McArdle, and M. J. Jackson, "Denervated muscle fibers induce mitochondrial peroxide generation in neighboring innervated fibers: role in muscle aging," Free Radical Biology and Medicine, vol. 112, pp. 84-92, 2017.

[45] M. Almeida, "Aging mechanisms in bone," BoneKEy Reports, vol. 1, 2012.

[46] P. Hubert, S. Lee, S.-K. Lee, and O. Chun, "Dietary polyphenols, berries, and age-related bone loss: a review based on human, animal, and cell studies," Antioxidants, vol. 3, no. 1, pp. 144-158, 2014.

[47] A. Varela-López, J. Ochoa, J. Llamas-Elvira et al., “Age-related loss in bone mineral density of rats fed lifelong on a fish oilbased diet is avoided by coenzyme Q10 addition," Nutrients, vol. 9, no. 2, p. 176, 2017.

[48] S. Hooshmand, S. C. Chai, R. L. Saadat, M. E. Payton, K. Brummel-Smith, and B. H. Arjmandi, "Comparative effects of dried plum and dried apple on bone in postmenopausal women," British Journal of Nutrition, vol. 106, no. 6, pp. 923-930, 2011.

[49] J. Zhang, O. P. Lazarenko, M. L. Blackburn et al., "Feeding blueberry diets in early life prevent senescence of osteoblasts and bone loss in ovariectomized adult female rats," PLoS One, vol. 6, no. 9, 2011.

[50] B. T. Tung, "Antioxidant and acetylcholinesterase inhibitory activities of ginger root (Zingiber officinale Roscoe) extract," Journal of Complementary and Integrative Medicine, vol. 14, no. 4, 2017.

[51] A. Fahmi, N. Hassanen, M. Abdur-Rahman, and E. ShamsEldin, "Phytochemicals, antioxidant activity and hepatoprotective effect of ginger (Zingiber officinale) on 
diethylnitrosamine toxicity in rats," Biomarkers, vol. 24 , no. 5 , pp. 436-447, 2019.

[52] D. T. Leal, G. G. Fontes, J. K. D. Villa et al., "Zingiber officinale formulation reduces hepatic injury and weight gain in rats fed an unhealthy diet," Anais da Academia Brasileira de Ciências, vol. 91, no. 4, 2019.

[53] A. B. Oyenihi, S. O. P. Langa, S. Mukaratirwa, and B. Masola, "Effects of Centella asiatica on skeletal muscle structure and key enzymes of glucose and glycogen metabolism in type 2 diabetic rats," Biomedicine \& Pharmacotherapy, vol. 112, p. 108715, 2019.

[54] H. M. Gong, Y. K. Lee, B. H. Lee, J. S. Kim, and H.-J. Lee, “The effects of dokhwalgisaeng-tang against disuse muscle atrophy in gastrocnemius of rats," Journal of Acupuncture Research, vol. 35, no. 4, pp. 207-213, 2018.

[55] Y. Ding, X. Dai, Y. Jiang et al., "Grape seed proanthocyanidin extracts alleviate oxidative stress and ER stress in skeletal muscle of low-dose streptozotocin- and high-carbohydrate/ high-fat diet-induced diabetic rats," Molecular Nutrition \& Food Research, vol. 57, no. 2, pp. 365-369, 2013.

[56] S. S. Reddy, K. Shruthi, Y. K. Prabhakar, G. Sailaja, and G. B. Reddy, "Implication of altered ubiquitin-proteasome system and ER stress in the muscle atrophy of diabetic rats," Archives of Biochemistry and Biophysics, vol. 639, pp. 16-25, 2018. 